Phronesis 65 (4): 414-466. 2020.

\title{
Aristotle on the Unity of the Nutritive and Reproductive Functions
}

\author{
Cameron F. Coates \\ DePaul University \\ ccoates@depaul.edu \\ James G. Lennox \\ University of Pittsburgh \\ jglennox@pitt.edu
}

\begin{abstract}
In De Anima 2.4, Aristotle claims that nutritive soul encompasses two distinct biological functions: nutrition and reproduction. We challenge a pervasive interpretation which posits 'nutrients' as the correlative object (antikeimenon) of the nutritive capacity. Instead, the shared object of nutrition and reproduction is that which is nourished and reproduced: the ensouled body, qua ensouled. Both functions aim at preserving this object, and thus at preserving the form, life, and being of the individual organism. In each case, we show how Aristotle's detailed biological analysis supports this ontological argument.
\end{abstract}

\section{Keywords}

antikeimenon; nutrition; nutritive soul; one-in-form; reproduction; self-maintenance

\section{Introduction}

While caring for her developing brood in a protective lair, the female octopus stops eating, starving herself to death in the process. This kind of reproductive behavior is not unusual in the animal kingdom. Aristotle was remarkably knowledgeable about octopus reproduction, including the apparently selfsacrificial behavior of the female in caring for the fertilized eggs. As he reports in the Historia Animalium $(5.12,544 \mathrm{a} 13-15)$ :

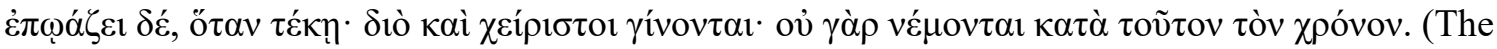
females, having laid their eggs, brood over them; wherefore the females also become very weak; for they do not feed themselves during this period. $)^{1}$

\footnotetext{
${ }^{1}$ Unless otherwise noted, all translations are our own.
} 
In such cases, it appears that nutrition is given up in the interests of reproduction. And yet Aristotle repeatedly insists that the nutritive and reproductive capacities are, in some sense, one and the same (e.g. $D A 2.4,416$ a19-21; GA 2.1, 735a15-20). In Section 2 of this paper, we point to a number of problematic features of this idea; in subsequent sections we defend a new way of understanding this identification, with the aim of resolving these problems.

\section{Problems}

In this section, we characterize two major problems with Aristotle's claim that the nutritive and the reproductive are functions of one and the same capacity. ${ }^{2}$

\subsection{Problem 1: One antikeimenon or Two?}

The first problem is fairly obvious, and has been bothering commentators on the De Anima from ancient times to the present. The discussion of the nutritive soul is preceded by a methodological prescription that Aristotle insists applies to all of the capacities to be discussed (DA 2.4, 415a14-22):

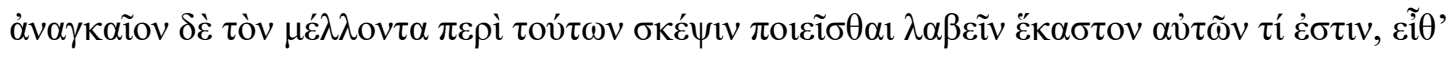

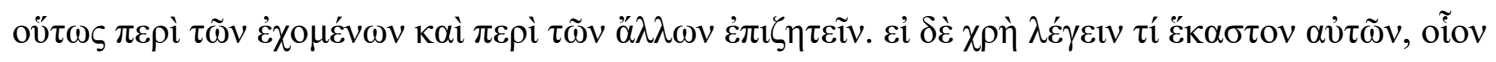

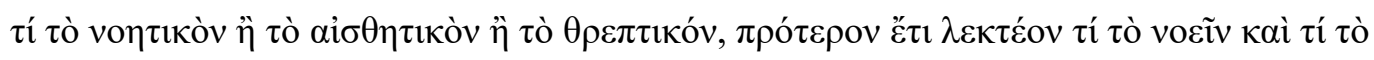

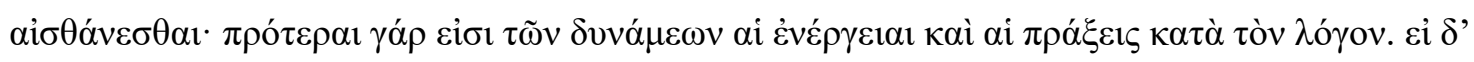

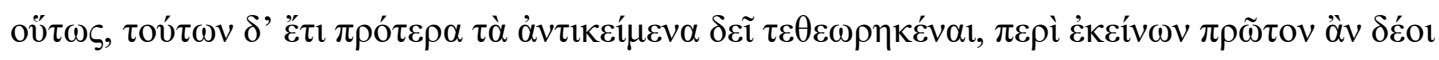

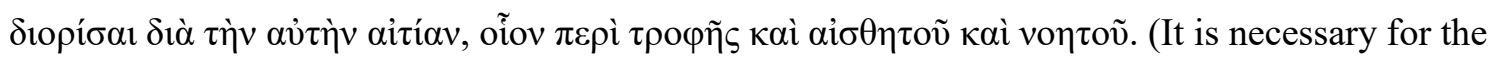
one who is going to make an investigation concerning these things [i.e. concerning the different capacities of soul] to grasp what each of them is, and then to seek out in this way their features and the other things about them. But if it is needed to say what each of them is, i.e. what the capacity of thought, of perception or of nutrition is, prior to this it would be necessary to say what thinking is, and what perceiving is, for activities and actions are prior in account to capacities. If this is so, and if further it is necessary to have examined the objects prior to those [activities],

\footnotetext{
${ }^{2}$ In this section of the paper we develop ideas originally presented by Lennox at a conference in Berlin in 2017; cf. also Lennox forthcoming.
} 
then first it would be necessary, on account of the same cause, to make distinctions concerning these things: concerning nourishment ${ }^{3}$ and the perceptible and the intelligible.)

We have here (albeit framed conditionally) two claims of priority, which leads to a normative recommendation about the proper way to study the capacities of the soul and which we will call the Double Priority Principle (DPP). There is a priority in account of activity to capacity, and a similar priority of the correlative object (antikeimenon) of the activity to the activity itself. But the DPP creates an immediate problem as Aristotle begins his discussion of the nutritive soul in the very next sentence (DA 2.4, 415a22-6):

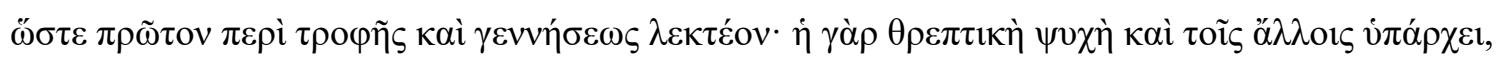

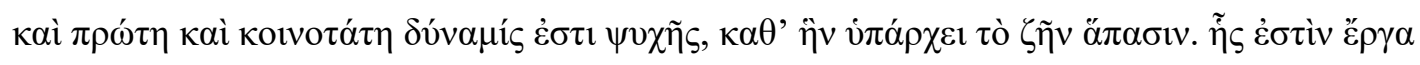

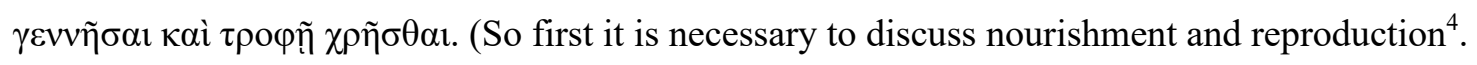
For the nutritive soul also belongs with the others ${ }^{5}$ and is the first and most common capacity of soul, by virtue of which life belongs to all. The functions of [this capacity] are to reproduce and to use nourishment.)

When this statement is considered in light of the two different 'priorities' in the DPP, it raises an obvious question: Why is this a single capacity of the soul? Aristotle is discussing two apparently quite different functions (erga), i.e. two different activities: reproducing and nourishing oneself. But if activities are prior in account to capacities, should there not be two capacities, rather than one? Despite this, Aristotle clearly thinks that these two functions do belong to a single capacity. But then surely, given the priority of the corresponding 'correlative objects' (ta antikeimena) to their activities, those activities ought to share a

\footnotetext{
3 'Nourishment' is ambiguous, in a way that mirrors the ambiguity in the Greek $\tau \rho \circ \varphi \eta$, between the nutritive capacity and the nutrients used by that capacity. This ambiguity plays an important role in our argument; when necessary, we will perform the needed disambiguation.

${ }^{4}$ It is very common for translators to ignore the distinction in the Greek between $\gamma \varepsilon \dot{\varepsilon} v \eta \sigma \iota \varsigma / \gamma \varepsilon v v \tilde{\alpha} v$ and $\gamma \varepsilon \dot{\varepsilon} v \sigma 1 \zeta /$ $\gamma$ í $\gamma \varepsilon \varepsilon \sigma \theta \alpha 1$, a practice encouraged by the fact that (as here) there is often manuscript support for both. But the former is typically restricted to acts of biological reproduction, while the latter refers to any process of coming to be. When it is important to stress this, we will use restrictive terms such as begetting or reproduction for $\gamma \varepsilon \dot{\varepsilon} \eta \eta \sigma i \zeta$ and its cognates. This point is also stressed in Lefebvre forthcoming.

${ }^{5} \tau$ oĩ $\check{\alpha} \lambda \lambda$ orৎ at $415 \mathrm{a} 24$ does not have a clear referent in the immediate context. Translators usually construe it as meaning nutritive soul belongs to 'the other living things'. But, given that this discussion follows immediately after the closing argument of $D A 2.3$, more likely it refers to how the higher types of soul presuppose the presence of the

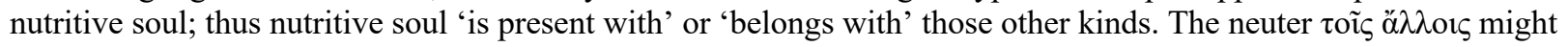

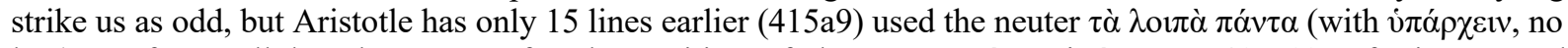

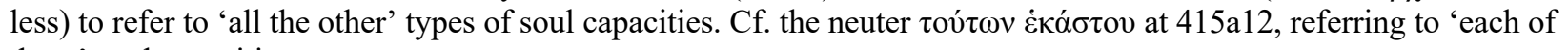
these' soul capacities.
} 
single correlative object, if they are to comprise a single capacity of soul. Yet it is hard to imagine how that could be so. Indeed, it is difficult to see how Aristotle's insistence on the unity of the nutritive and reproductive functions can square with either of the requirements he sets with the DPP.

Now one might think this cannot be a real problem or, if it is, it is not unique to the nutritive soul. After all, there are five different perceptible objects corresponding to five different modes of perceiving, yet Aristotle treats the perceptive soul as a single dunamis. The cases are not, however, parallel: for each kind of perception, the correspondence between the correlative and the perceptive activity is essentially the same. Either directly, or via motions in the medium, the 'sensible object' acts on the sense organ, and all such information is conveyed to the seat of the common sense, the heart. Similarly, in cases of cognition it is at least initially plausible to consider the antikeimena as 'intentional objects'. By contrast, the relevant organs involved in converting food into blood and then into tissues and organs seem to be different in every way from those engaged in the activities of reproduction. Indeed, Aristotle never explicitly refers to a common correlate of the reproductive and nutritive activities as an 'antikeimenon', and it is far from clear how it could be one and the same. ${ }^{6}$

\subsection{Problem 2: Why not 'the Reproductive Soul'?}

Immediately after the statement of the DPP, in rapid succession, Aristotle makes the following three claims:

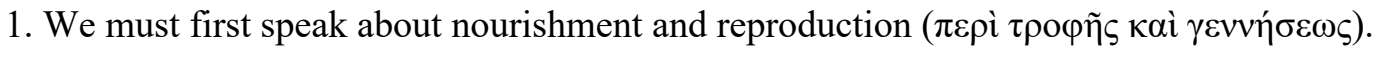

2. The discussion concerns a single most common capacity of the soul - which he refers to as the nutritive capacity or nutritive soul.

3. There are two functions of this capacity, nourishment and reproduction.

This blithe switching between singular capacity of soul and two quite different functions runs through the entire chapter and is found in a number of other places, as we will see. Given that Aristotle claims that this capacity of the soul is expressed in two distinct activities, why does he treat them as functions of the nutritive capacity and not the reproductive? After all, in DA 2.4 and elsewhere, Aristotle grants clear priority to the reproductive function over nutrition. Immediately after the text we have been discussing, for example, he refers to reproduction as 'the most natural of functions for living things' ( $D A 2.4,415 \mathrm{a} 26$ 9; cf. GA 2.1, 735a18-19) - and the inferential $\gamma \alpha \dot{\alpha} \rho$ at 415a26, which introduces that claim, suggests that

\footnotetext{
${ }^{6}$ See Johansen 2012, 93-102.
} 
going directly to reproduction somehow follows from the fact that there are these two functions of the nutritive soul.

Why, then, we might ask, not call this 'the reproductive soul'? Late in the chapter, as he is wrapping up his account of this most common soul capacity, he makes this very suggestion $(D A 2.4$, $416 \mathrm{~b} 23-5):^{7}$

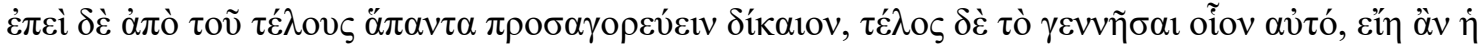

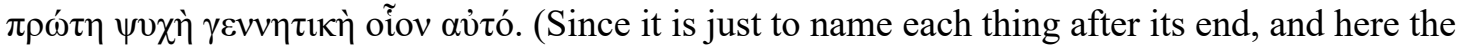
end is to reproduce another such as itself, the primary soul would be reproductive of another such as itself.)

Aristotle is at least raising the question of whether it would be just to refer to this soul as the reproductive soul, not the nutritive soul!

A similar prioritization of reproduction is found elsewhere, e.g. in an important passage in the Historia Animalium, near the beginning of Aristotle's investigation into the different ways of life of animals. In fact, in this passage reproduction is said to be the only function that plants and sessile animals have - nutrition is not even mentioned! $H A 7(8) .1,588 \mathrm{~b} 23-30$ :

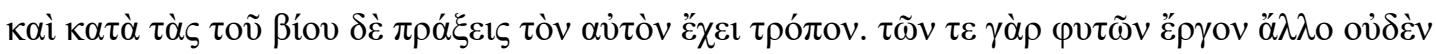

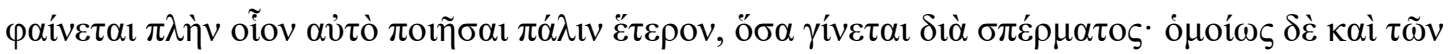

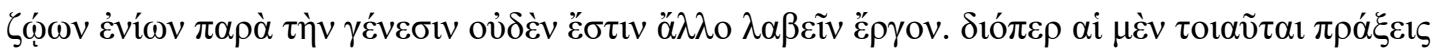

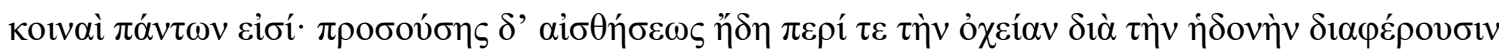

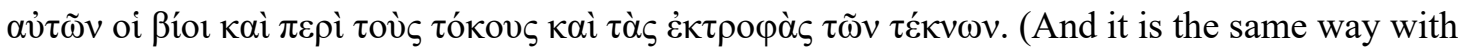
respect to the activities that constitute their way of life [as it is with their parts]. For as many plants as come to be from seed appear to have no other function than to produce another like themselves; and similarly in certain animals too [i.e. those without locomotion] there is no other function to grasp apart from generation. Wherefore, while activities such as these are common to all, as soon as perception is added their ways of life differ in regard to mating (due to the [awareness of] pleasure) and with regard to birth and the rearing of young.)

${ }^{7}$ The text is from Ross. For reasons having to do with his understanding of the argument, Torstrik moved b20-3 so they appear after this passage rather than before. Ross accepted this emendation (Ross 1961, 231) but without changing the Bekker numbers. Shields also accepts it, but does change the line numbers (Shields 2016, 76 n. 20), so that this passage is at $416 \mathrm{~b} 18-19$ in his translation. 
Lest one think that the stress on reproduction here is due to nutrition not being in focus, it is important to note that just a few lines later in this passage nutrition is mentioned, along with reproduction (HA 7(8).1, 589a2-7):

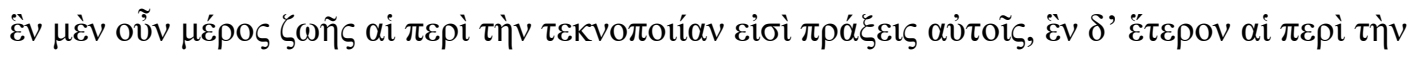

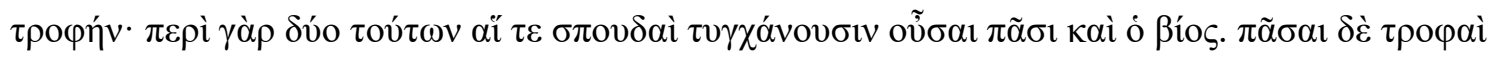

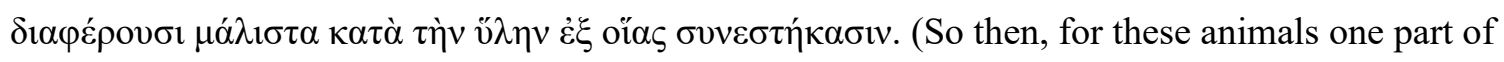
life consists in activities related to the producing of young, another part is activities concerning nourishment; for the way of life and the efforts in all these animals are in fact concerned with these two things. And all the kinds of nourishment differ chiefly according to the matter out of which they are constituted.)

Aristotle is drawing our attention to the fact that more intelligent and social animals expend a good deal of time and energy on feeding their young. That is, nutrition comes up in this passage because for such animals feeding their young is a critical aspect of successful reproduction. Otherwise, the first and most common function of living things, and the only one found in plants, is reproduction. The same message comes through clearly at the end of book one of the Generation of Animals, in discussing why male and female capacities are united in plants but separated in most animals (1.23, 731a24-32):

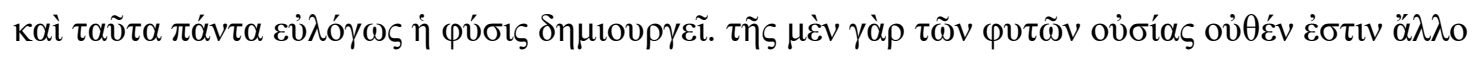

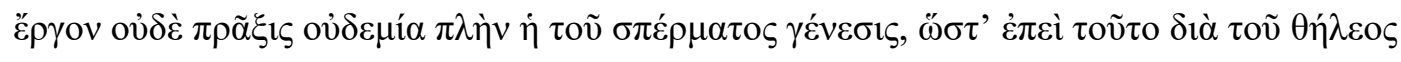

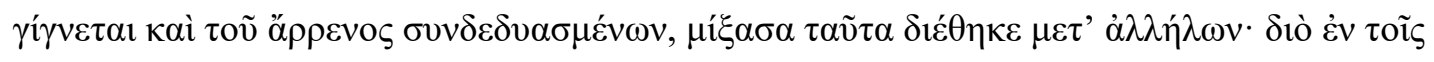

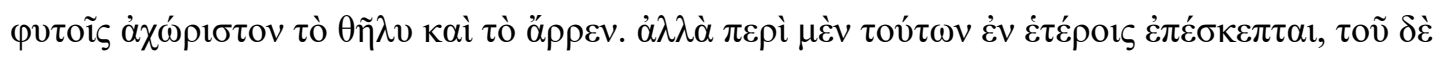

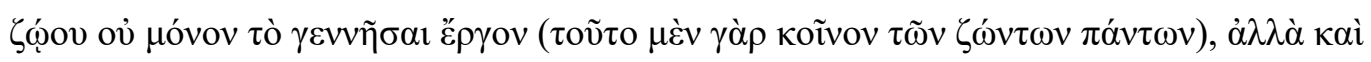

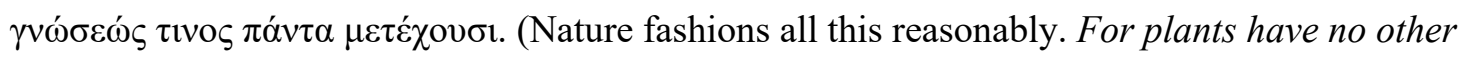
function or activity of their being except the generation of seed, so that since this is done through coupling of male and female, nature has arranged them together by mingling them; this is why male and female are inseparable in plants. But these matters were investigated elsewhere; and the animal's function is not only to reproduce (for that is common to all living things), but also to participate in some sort of cognition. $)^{8}$

\footnotetext{
${ }^{8}$ This passage highlights the way in which Aristotle uses the terms $\gamma \varepsilon \dot{\varepsilon} \varepsilon \sigma ı \varsigma$ and $\gamma \varepsilon \dot{v} v \eta \sigma ı \varsigma$ - here the former term is used to characterize the production of seed, while the verb corresponding to the latter term is used of the biological function of making another like itself.
} 
In passages such as these, even the fact that plants also absorb nutrients from the soil in order to maintain themselves goes entirely without mention - it is explicitly said that their only function is to produce seed and to reproduce more plants just like themselves.

And yet: returning to $D A 2.4$, in an obvious reference to the DPP (after having offered a stirring teleological explanation for reproduction, which we will turn to in due course), we read ( $D A$ 2.4, 416a1921):

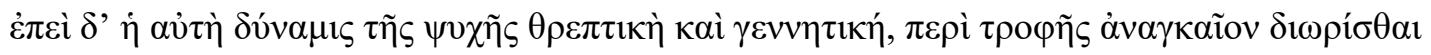

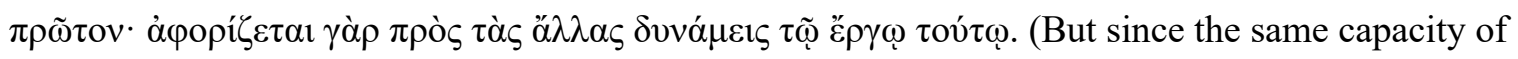
soul is nutritive and reproductive, first it is necessary to make determinations about nourishment, for it [this one capacity of the soul] is distinguished from the other capacities by this function.)

Capacities are, according to the DPP, demarcated by reference to their function or activity. But according to the same principle, the function or activity corresponding to the capacity is demarcated by reference to their correlative objects. Our first order of business, then, is to understand what an antikeimenon of a psychic activity is. Then we can address the problem of whether there might be a single antikeimenon correlative to the two functions of the nutritive soul.

\section{What is an antikeimenon?}

Despite the obvious methodological importance of the concept of an antikeimenon to the discussion of identifying the various parts and functions of the soul in the $D A$, there is no explanation of the term within this text. Indeed, the word itself is only used five times in the $D A$, and in only three of these instances is it used in the sense of a correlative to a capacity of soul. ${ }^{9}$ However, its usage in the $D A$ relies on discussions concerning relations in the Categories, Topics and Metaphysics, so we will turn to those discussions for a better understanding of this concept.

Cat. 7 categorizes the soul's capacities of perception (aisthèsis) and knowledge (epistēmē) as kinds of relatives, specifically as relative to the perceivable object (to aisthèton) and the knowable object

\footnotetext{
${ }^{9}$ Apart from its appearance in our passage at $D A 2.4,415 \mathrm{a} 20$, the word is used in a similar methodological context at $D A 1.1,402 \mathrm{~b} 15$ : here the topic is soul division and Aristotle expresses in similar terms the need to investigate to aisthèton and to noēton before their corresponding capacities (no mention is made of nutrition here). At DA 2.11, 424a11, it is used to refer to the whole array of different kinds of perceptible objects, such as the visible, tangible etc., and, 'in a certain way', to the absence of those objects (the invisible, the intangible etc.). At $D A 1.5,411 \mathrm{a} 4$, it is used to refer to diametrically opposed contraries rather than to the 'object' of a capacity. At $D A 2.4,416 \mathrm{a} 34$, the word is used to refer to the terminus ad quem of a change between diametrically opposed conditions.
} 
(to epistēton) (6b33-6). ${ }^{10}$ Later, he calls the type of relation that holds between these capacities and their objects one of 'opposition' or 'lying opposite to one another' (antikeisthai) (Cat. 10, 11b24-33). ${ }^{11}$

Aristotle argues at length in the Categories for a distinction between soul-object relations and other types of relations. The distinction is drawn, broadly speaking, in terms of ontological dependence. ${ }^{12}$ Aristotle claims that 'most' relatives are 'simultaneous by nature' (Cat. 7, 7b15-22) because they 'reciprocate as to implication of being' (cf. Cat. 12, 14a29-35; 13, 14b27-33): when relative $x$ exists, its correlative $y$ also exists and vice versa. Soul-object relations do not share this reciprocity: if there is perception, there must be something perceivable that the perception is of; but if there is something perceptible, there need not be any actual perception of it (Cat. 7, 7b22-8a12). The objects are thus ontologically 'prior' to the soul's capacities, for knowledge and perception depend for their being on the knowable and the perceivable, but the objects are not dependent on the capacities. ${ }^{13}$ Metaph. $\Delta .15$ cashes out this distinction between types of relations in terms of definitional (or essential) dependence (1021a26-31):

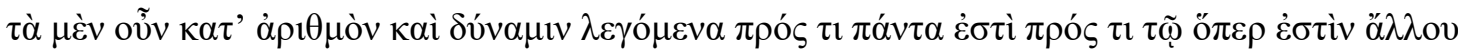

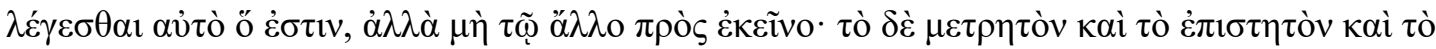

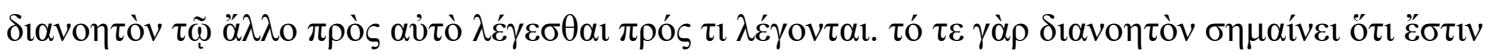

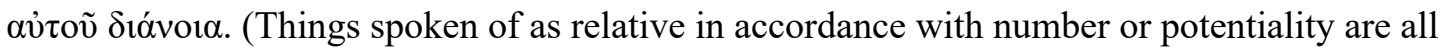
relatives from being called just what they are of something else, not from the other thing being relative to them. But the measurable and the knowable and the thinkable are called relatives from

\footnotetext{
${ }^{10}$ Cf. Metaph. $\Delta .15,1020 \mathrm{~b} 30-2$.

${ }^{11}$ For antikeimena as relatives, cf. Metaph. $\Delta .10,1018 \mathrm{a} 20-2$.

${ }^{12}$ Sedley 2002 has argued that Cat. 7 introduces a distinction between two degrees of relations, 'hard' and 'soft', with knowledge and perception counting only as 'soft' relatives on account of the fact that these capacities and their objects do not abide by the 'principle of cognitive symmetry' (i.e., in our terms, that the two relata are not definitionally co-dependent). Sedley admits, however, that Aristotle does not follow the restriction to 'hard' relativity outside of the second half of Cat. 7, and regularly uses knowledge and perception as examples of relatives. We suggest that Aristotle is more interested in distinguishing types of relations based on the kinds of dependence at play between relata than in restricting the category to only one such type. For critical responses to Sedley's interpretation, see Harai 2011 and Duncombe 2015.

${ }^{13}$ The dependence described in the Categories is thus a kind of modal-existential dependence akin to the kind of 'priority' articulated at Metaph. $\Delta .11,1019 \mathrm{a} 1-4$ : if $x$ is capable of being without $y$, but $y$ is not capable of being without $x$, then $y$ is ontologically dependent on $x$ (or, as Aristotle puts it, $x$ is ontologically 'prior' to $y$ ). Aristotle explicates the priority of the objects over their corresponding capacities in causal terms at Metaph. Г.5, 1010b301011a2. The question of how precisely Aristotle understands ontological dependence is debated in the literature; for a concise overview of the available interpretations, see Corkum 2016. In the context of that debate, it is noteworthy that Aristotle describes the dependence of the soul's capacities on their correlatives in modal-existential, essential, and causal terms in different contexts.
} 
something else being called [what it is] relative to them. For 'the thinkable' signifies that thinking is of it. $)^{14}$

Numerical relatives and relatives in respect of potentiality are involved in symmetrical relations: $x$ is related to $y$ and vice versa. The reason for this symmetry is that such relatives are definitionally codependent: each relative is defined by reference to the other, such that the essence-specifying account of relative $x$ makes explicit reference to its correlative $y$ and vice versa. The definition of a numerical relative includes reference to its correlative: what it is to be a 'half' just is to be related to another quantity in a proportion of 1:2, and to be a 'double' is the inverse (cf. Top. 6.9, 147a29-31). Hence the 'double' must be included in the account of the 'half' and vice versa. ${ }^{15}$ Similarly, the definition of being 'capable of heating' includes reference to what can be heated, and the definition of 'capable of being heated' includes reference to the action of what can heat. All relatives that are definitionally dependent on their correlatives are said to have a 'per se' relation to their correlative (Top. 6.4, 142a26-31), and so each numerical relative and each relative in respect of potentiality has a symmetrical relation with their corresponding correlatives. For such relatives, Aristotle claims, 'being is the same as being relative in some way' (Cat. 7, 8a39-b1).

Soul-object relations, by contrast, are asymmetrical. They are asymmetrical because, while the soul's capacities are defined ('called just what they are') by reference to their objects, the object is not defined by reference to the capacity. The being (ousia) of each sense is by nature relative to its proper object ( $D A$ 2.6, 418a24-5); the definition of vision, for example, must make reference to color. But colors are real features of beings in the world, independent of their capacity to be seen. Color is that which is

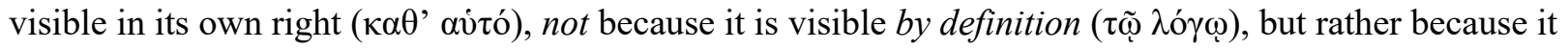
has in itself the cause of its being seen (DA 2.7, 418a29-31). ${ }^{16}$ Hence color is not the same as being visible

${ }^{14}$ We have altered the Kirwan 1993 trans. slightly.

${ }^{15}$ Cf. Top. 6.4, 142a22-33: for relatives like 'double' or 'half', for which 'being is the same as being relative in some way ... it is impossible to know the one [relatum] without knowing the other; for this reason it is necessary for the one to be included in the account ('่v $\tau \tilde{\omega} \ldots \lambda$. . ó $\left._{\omega} \omega\right)$ of the other'.

${ }^{16}$ Cf. Polansky 2007, 265-6 with n. 5. Aristotle is at pains to distinguish the causality involved in soul-object relations from that involved in relations in respect of potentiality. Insofar as the perceptible object is the cause of actual episodes of perception, this causal relation is analogous to that between, e.g., what heats and actual episodes of being heated. But Aristotle emphasizes that the analogy breaks down when considering their status as relatives: 'For surely perception is not of itself; rather, there is something else, distinct from the perception, which is necessarily prior to the perception. For that which moves is by nature prior to that which is moved, and even if these [i.e. that which moves and that which is moved] are said to be relative to one another, this is nonetheless so' (Metaph. Г.5, 1010b35-1011a2). The causal priority of the perceptible to perception does not imply a reciprocal relation between them, as it does between what moves and what is moved. In $D A 2.5$, Aristotle provides an extended analysis of the difference between qualitative alteration on the one hand and perception and thinking on the other. 
(Phys. 3.1, 201b3-4; Metaph. K.9, 1065b32-3). The being of color is not 'the same as being relative in some way' to perception, and so the definition of color need not make any reference to color's potential to affect the sense organs of animals. ${ }^{17}$ Thus antikeimena are relative to the soul's corresponding capacities in a way, but only by virtue of these capacities being definitionally dependent on them. The capacities of perception, knowledge and thought are related in a per se way to their objects, but these objects themselves do not have a per se relation to their corresponding capacities. ${ }^{18}$

\section{What is the antikeimenon of the Nutritive Capacity?}

These discussions of relations in the Categories, Topics and Metaphysics $\Delta$ are important to understanding the motivation behind the DPP in $D A$ 2.4. If the soul's capacities are account-dependent on their objects (but not vice versa), then Aristotle has good reason to insist in $D A 2.4$ that an account of the objects must precede an account of the activities, and thus of the capacities, that correspond to them, for the account of the capacity and its activity necessarily includes reference to the object (but not vice versa). His analysis of relations is also important to correctly identifying the antikeimenon of the capacity of nutrition (to threptikon) in particular, notwithstanding the fact that the discussions in the Categories, Topics or Metaphysics $\Delta$ do not address nutrition or its corresponding antikeimenon.

Commentators typically identify the nutrients consumed by plants and animals as the relevant correlate for the activity of nutrition. ${ }^{19}$ Just as the capacity of thought (to noêtikon) corresponds to the object of thought (to noèton), and the capacity of perception (to aisthêtikon) corresponds to that which is

The former, he says, is always a partial destruction of that which is affected; the latter is rather a 'preservation' (sōteria) of the capacity to perceive or think (DA 2.5, 417b2-16).

${ }^{17}$ Rather, color is related as a relative in respect of potentiality (pros ti kata dunamin) to the visible medium. The nature of color is to be a capacity to set the transparent medium in motion, such that whenever the medium is illuminated, color acts on it ( $D A$ 2.7, 418a31-b2; 419a9-11). The transparent medium is also defined by reference to color: it is what is visible by virtue of the color of some other body ( $D A 2.7,418 \mathrm{~b} 4-6)$. Color and the transparent medium thus share a symmetric relation. But the fact that some animals possess color-sensitive organs which can be affected in turn by this medium does not bear on the essential nature of color qua color.

${ }^{18}$ Ross notes that Aristotle seems to waffle on whether the antikeimena are related to the soul's corresponding capacities in a per se or per accidens way: at Metaph. $\Delta .15,1021 \mathrm{~b} 3-4$ he appears to class them among per se relatives, but later, at Metaph. I.6, 1056b32-1057a1, he classes them as per accidens relatives (with a direct reference to Metaph. $\Delta .15)$ (Ross 1948, 331). We are convinced by Ross's suggestion on how to reconcile the two claims: while the perceptible etc. are per accidens relatives in the sense that they are only relative to the capacities by virtue of the capacities' relation to them, they are in a way per se relatives in the sense that 'it is they and not something of which they are mere accidents that are relative; they are not relative in the incidental way in which 'the man' is so (1021b8)' (Ross 1948, 331).

${ }^{19}$ E.g. Apostle 1981, 107; Aquinas, On the De Anima $\$ 306$ (trans. Foster and Humphries 1951, 209); Averroes, On the De Anima II.18 (trans. Taylor 2009, 142-43); Diamond 2015, 77; Everson 1991, 176-77; Gill forthcoming; Hamlyn 1993, 95; Hicks 1907, 339; Johansen 2012, 96-102; Menn 2002, 118; Polansky 2007, 202; Ross 1961, 2278; Shields 2016, 199. 
perceivable (to aisthèton), so the nutritive capacity (to threptikon), it seems, should correspond to that which is edible, or consumable. But Aristotle has no readily available verbal adjective corresponding to to threptikon that would parallel to noèton or to aisthēton. The difficulty is compounded by the fact that, as noted earlier, the word Aristotle uses to refer to food or nutrients (he trophē) refers in other instances to the capacity of nutrition itself (and in those cases is referentially identical to the term to threptikon) or to the activity of this capacity. ${ }^{20}$ This presents a challenge for translation and interpretation that has not been adequately appreciated in the literature. In this section of the paper, we begin by calling into question the standard interpretation regarding the antikeimenon of nutrition. The standard reading of the chapter posits food as the antikeimenon of nutritive activity on the basis of 415a20-2. We suggest instead an alternate reading of these lines, which leaves open the question of what qualifies as the antikeimenon of nutritive activity. We go on to show that there are good reasons to reject the identification of the antikeimenon of nutrition with food, and we argue that it is not until $D A 2.4,416 \mathrm{~b} 9-11$ that Aristotle articulates this antikeimenon: the ensouled body qua ensouled. Not only does our account avoid the problems of the standard interpretation, it also draws a direct connection to the discussions of relatives that form the background of the DPP. What it means that the ensouled body qua ensouled serves as the antikeimenon of nutrition is the topic of Section 5 of the paper; how the ensouled body qua ensouled also serves as the antikeimenon of reproduction will be addressed in Section 6.

Consider $D A 2.4,415 \mathrm{a} 20-2$, which is universally taken by commentators to specify the three antikeimena corresponding to intellect, perception, and nutrition:

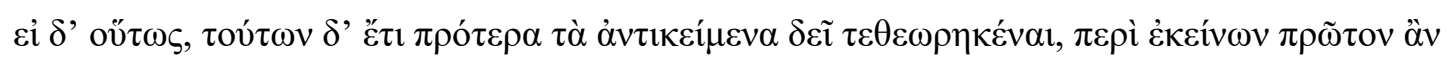

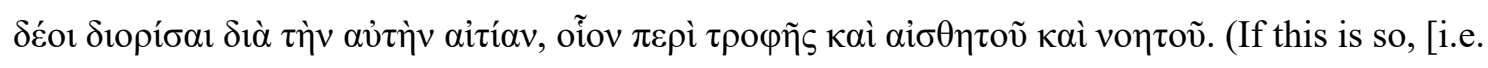
if the activities are prior in account to the capacities] and if further it is necessary to have examined the objects prior to those [activities], then first it would be necessary, on account of the same cause, to make distinctions concerning these things: concerning nourishment and the perceptible and the intelligible.)

\footnotetext{
${ }^{20}$ The ambiguity is widely remarked upon (e.g. Hamlyn 1993, 95; Hicks 1907, 339; Shields 2016, 199). While Ross contends that Aristotle was 'careless' in his choice of words (1961, 227), Polansky argues that the ambiguity is intentional (2007, 202 n. 2). Matters are further complicated by the fact that Aristotle sometimes uses the term to threptikon to refer to nutrients rather than the capacity (cf. De Sensu 1, 436b17-18 and the commentary on the variant readings ad loc. in Ross 1955); cf. similar usage at De Sensu 5, 443b21, 445a30-1 and 6, 445a8-9. Of the thirty-five instances of the word trophe in the text of $D A$, twenty-three are to be found within $D A 2.4$ and twelve elsewhere. Of these twelve, three refer to the capacity and / or its activity $(412 \mathrm{a} 14 ; 413 \mathrm{a} 24,31)$, eight refer to nutrients $(412 \mathrm{~b} 4 ; 414 \mathrm{~b} 6,7,10 ; 421 \mathrm{~b} 12 ; 434 \mathrm{~b} 18,19 ; 435 \mathrm{~b} 24)$, and one $(434 \mathrm{a} 25)$ is ambiguous (but likely refers to the capacity / activity).
} 


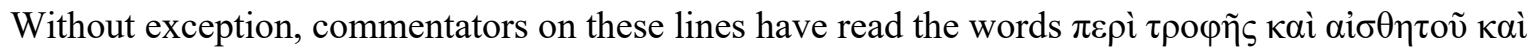

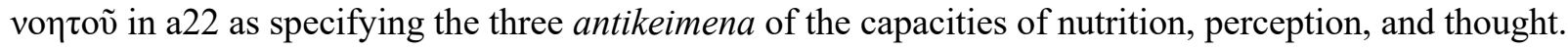
This is, we agree, the most straightforward reading of the lines: if the activities are prior in account to the capacities, and the objects are prior in account to the activities, then first it would be necessary to make

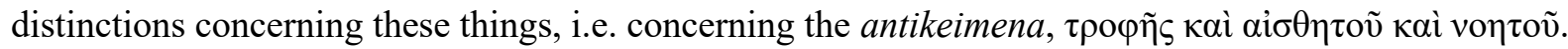
On this reading, $\tau \rho \circ \varphi \tilde{\eta} \varsigma$ in a22 could not possibly refer to the capacity or activity of nutrition, for presumably the capacity/activity cannot have itself as its own object (as this would subvert the very priorities Aristotle has just established). As such, the word $\tau \rho \circ \varphi \tilde{\eta} \varsigma$ is always translated as 'food' or the like, and this is taken to be the antikeimenon of the nutritive capacity.

The standard reading of 415a20-2, however, does not sit well at all with the immediately following words ( $D A$ 2.4, 415a22-6):

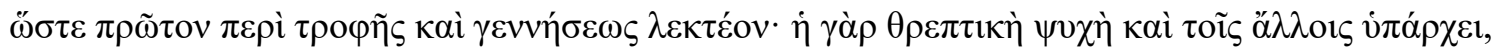

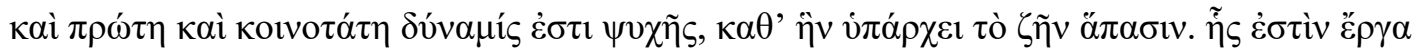

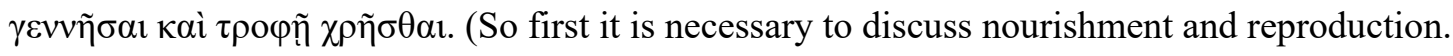
For the nutritive soul also belongs with the others and is the first and most common capacity of soul, by virtue of which life belongs to all. The functions of [this capacity] are to reproduce and to use nourishment.)

Here, in the very next clause after 415a20-2, Aristotle proceeds, without signaling any change in meaning, to use the word trophe to mean the activity of nutrition, not the nutrients. First, he says, it is necessary to discuss 'trophē and reproduction' ( is that in virtue of which all (perishable) living things are alive. Aristotle is invoking the first priority of the DPP: the capacity of nutritive soul is that in virtue of which all living things are alive, so first we must discuss the activities of that capacity, namely nutrition and reproduction. He then recapitulates the two

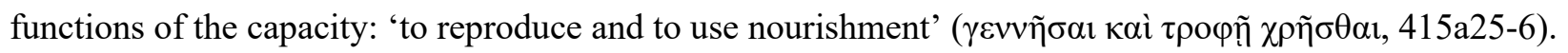
While $\tau \rho о \varphi \tilde{n} \chi \rho \tilde{\eta} \sigma \theta \alpha$ is typically taken to mean 'to make use of food', it is much more likely that it

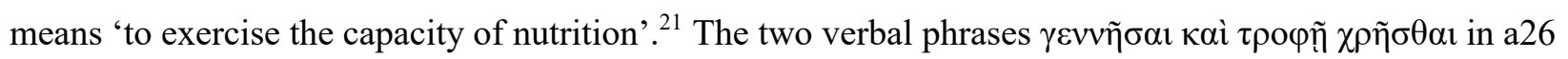
are simply a rephrasing of the two nouns $\tau \rho \circ \varphi \tilde{\eta} \varsigma \alpha \alpha i ̀ \varepsilon v v \eta ́ \sigma \varepsilon \omega \varsigma$ from a23, the verbal forms being more

${ }^{21} \chi \rho \alpha ́$ o $\mu \alpha \mathrm{r}$ with a dative noun is often used by Aristotle to mean 'to exercise a capacity': see e.g. EE 2.9, 1225b1112; 5.1, 1229b31-3; 6.10, 1143a11-16; Metaph. A.7, 1017a35-b6; PA 2.16, 659b30-4; Phys. 7.3, 247b1-248a9;

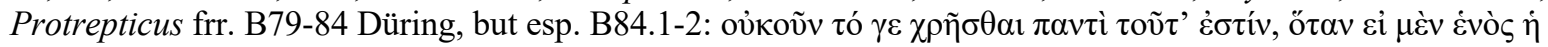

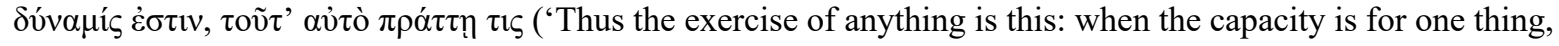
someone does this very thing'). Many other instances of such usage can be found across the corpus. 
explicitly and unambiguously erga than their noun counterparts. While one might expect an infinitive form of the verb $\tau \rho \varepsilon \dot{\varepsilon} \varphi \omega$ to pair with $\gamma \varepsilon v v \tilde{\eta} \sigma \alpha l$, the phrase $\tau \rho о \varphi \tilde{n} \chi \rho \tilde{\eta} \sigma \theta \alpha$ is actually a better way of expressing 'the activity of nutrition' than either $\tau \rho \varepsilon ́ \varphi \varepsilon \sigma \theta \alpha \mathrm{l}$ (as $\tau \rho \circ \varphi \tilde{n} \chi \rho \tilde{\eta} \sigma \theta \alpha \mathrm{l}$ is explicitly active in

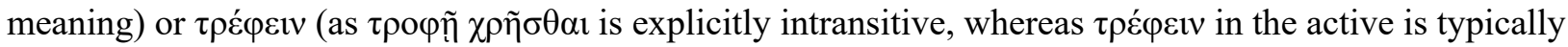

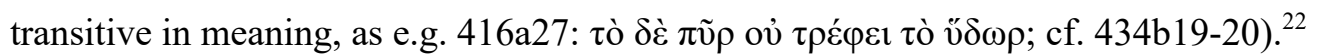

It is telling that Aristotle insists on the necessity of discussing the activities of nutrition and reproduction in the lines which directly follow 415a20-2. But this fact has been misunderstood by Aristotle's commentators. Consider Ross's complaint against all of 415a20-5 ad loc.:

The reasoning here is rather careless. A[ristotle] first says that we should study the objects of the faculties before we study the faculties themselves; and this is quite reasonable. Nutrition, for instance, being the absorption of food, we must know what food is before we can understand

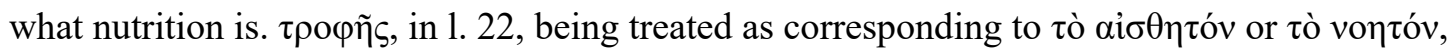
must mean 'food'; but in 1. 23, being parallel to $\gamma \varepsilon ́ v v \eta \sigma ı \varsigma$, it must mean 'the absorption of food'. In 11. 22-23 it is said to follow from what has just been said that we must treat first of nutrition and generation; but this in fact follows not from what has just been said, but from what follows in 11. 23-25, viz. that nutrition and generation as the basic faculties whose presence constitutes life.

Ross sees Aristotle's insistence on investigating the activities of nutrition and reproduction as a 'careless' incongruity with 415a20-2. However, Aristotle's reasoning is 'careless' only on the assumption that $\tau \rho \circ \varphi \tilde{\eta} \varsigma$ in a22 must specify the antikeimenon of nutrition and must mean 'food'. The Greek does not necessitate the standard reading of 415a20-2, however. In fact, it is perfectly possible to read $\tau \rho \circ \varphi \tilde{\eta} s$ in a22 as 'the activity of nutrition', and thus to read it not as a specification of the object of the activity. Reading 415a20-2 in this way refutes Ross's claim of carelessness. Let us see how such a reading is possible.

Here again are the lines in question (DA 2.4, 415a20-2):

\footnotetext{
${ }^{22}$ Nevertheless, it is certainly still possible to understand $\tau \rho \circ \varphi \tilde{n} \chi \rho \tilde{\eta} \sigma \theta \alpha \mathrm{l}$ as 'to make use of food', for variations on the phrase can be found elsewhere in the corpus which are closer to this in meaning. However, no other use of the phrase that we have found would correspond exactly to the idea of 'making use of food' specifically as a function of nutritive soul, nor even to the idea of 'making use of food' in general: all such instances appear in discussions of specific organs that are for 'using' or 'taking' food, of specific animals 'using' something as food, or of 'making use' of a specific kind of food or diet: see e.g. PA 4.4, 678b20; 4.6, 683a1; HA 1.1, 488a18; 7(8).11, 596b16; Prob. $1.15,861 \mathrm{a} 6-7 ; 21.13,928 \mathrm{a} 33-7 ; 28.1,949 \mathrm{a} 43$.
} 


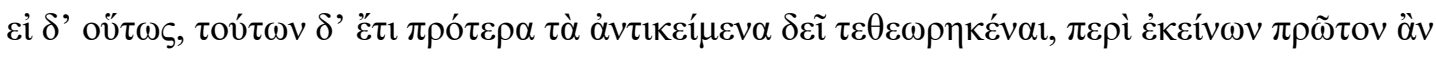

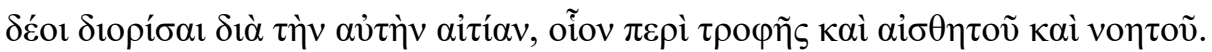

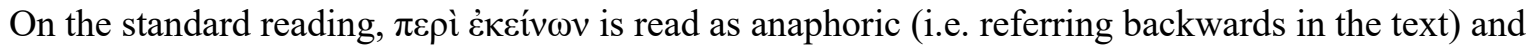
coordinate with $\tau \grave{\alpha} \dot{\alpha} v \tau \imath \kappa \varepsilon i ́ \mu \varepsilon v \alpha$. If $\pi \varepsilon \rho \grave{~} \dot{\varepsilon} \kappa \varepsilon i ́ v \omega v$ is coordinate with $\tau \grave{\alpha} \alpha \dot{\alpha} v \tau \imath \kappa \varepsilon i ́ \mu \varepsilon v \alpha$, then the expansion

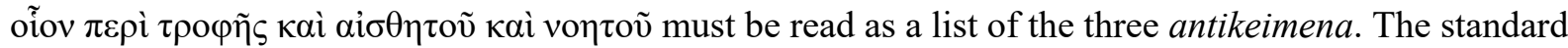
reading thus takes the apodosis of the conditional as articulating a specific need: a need to make distinctions about the three antikeimena (food, the perceptible, the intelligible) 'on account of the same cause', namely, on account of the specific priority of these antikeimena vis-à-vis the activities. We suggest an alternative reading, one which takes $\pi \varepsilon \rho \grave{~} \varepsilon$ $\kappa \varepsilon i ́ v \omega v$ as cataphoric (i.e. referring forwards), and to

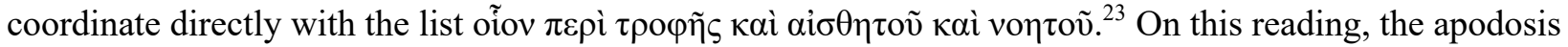
can be taken as stating instead a general need to investigate concerning the activity of nutrition, the perceptible object, and the intelligible object 'on account of the same cause', namely, on account of the DPP taken as a whole. The cataphoric reading thus makes it possible to take $\tau \rho o \varphi \tilde{\eta} s$ in a22 not as a specification of the antikeimenon of nutrition, but simply as the nutritive activity itself. On our reading, Aristotle is stating that (on account of the DPP) it is necessary to make distinctions about the activity of nutrition (among other things, about what in the world its object might be) and about what is perceptible and what is intelligible (which are more obviously the objects of their corresponding activities). This reading is not just possible, but prima facie likely, given that Aristotle goes on immediately thereafter to use the word trophe to refer to the activity of nutrition, not to the nutrients consumed. And this reading has the further benefit of showing (pace Ross) that Aristotle is not being 'careless' in his reasoning: if $\tau \rho о \varphi \tilde{\eta} \varsigma$ in a22 does not specify the antikeimenon of the activity but instead refers to the activity itself, then Aristotle's claims in a22-5 do follow from what he has just said in a20-2. Given the just-articulated DPP, first ( $\pi \rho \tilde{\omega} \tau o v, a 21)$ it is necessary to make distinctions about the activity of nutrition, the perceptible object, and the intelligible object; so that first (again, $\pi \rho \tilde{\omega} \tau o v, a 23$ ) it is necessary to speak about the activities of nutrition and reproduction, because the capacity for these activities also belongs in a way to the other capacities of soul (as Aristotle has argued in the previous chapter: cf. $D A 2.3,414 \mathrm{~b} 28-32$ ), making nutritive soul the first and most common capacity of soul. Discussion of the nutritive and reproductive activities comes first: in general because of the priorities articulated in the DPP, and in

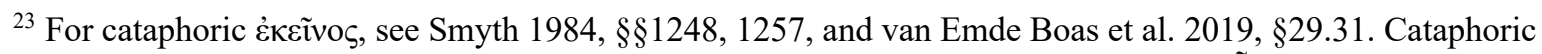

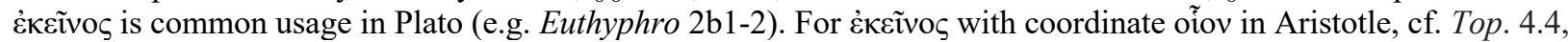

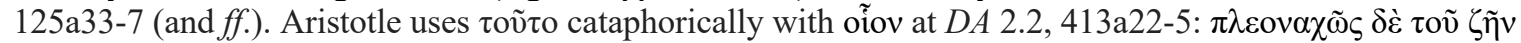

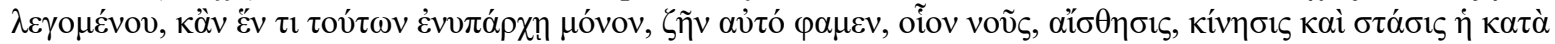

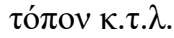


particular because of the nutritive soul's priority with respect to the other capacities of soul. Read in this way, Aristotle's reasoning is not 'careless', but rather perfectly legitimate and straightforward. Nor does this contravene Aristotle's claim that we should study the objects before the activities. If the antikeimenon itself is not known or specified, then what is needed first is a more general and wide-reaching investigation into nutrition and reproduction - which is manifestly what he goes on to pursue immediately after the lines in question (not a detailed analysis of a specific antikeimenon, 'food' or otherwise).

Which reading of 415a20-2 we choose has deep implications for our understanding of the rest of the chapter. On the standard reading of those lines, Aristotle simply states that food is the antikeimenon of nutrition; on our reading, he is actually holding open the question of what nutrition's antikeimenon might be. As we have seen, reading 415a20-2 our way is not only possible, but actually makes better sense of the lines in their immediate context. This consideration thus directly challenges the primary (indeed, sole) evidence for the standard interpretation regarding the antikeimenon of nutrition. In the remainder of this section, we first provide an alternative to the standard interpretation, suggesting that the antikeimenon of nutrition is in fact the ensouled body qua ensouled ( $D A 2.4,416 \mathrm{~b} 9-11)$. Then we proceed to strengthen our case against the standard interpretation by showing that Aristotle considers food to be a necessary condition of nutrition rather than its object. Finally, we adduce some corroborating evidence for our critique of the standard interpretation.

So far, we have restricted our examination to the opening lines of $D A 2.4$. There are several intervening discussions before Aristotle once again picks up the thread with which he began: a discussion of the final cause of reproduction (415a26-b7, which we return to in Section 6 below), a discussion of the soul as the cause and principle of the body (415b8-28), and an argument against Empedoclean and (perhaps) Heraclitean views of nutrition (415b28-416a18). The lines 416a19-21 then clearly mark a transition back to the topic of the nutritive function:

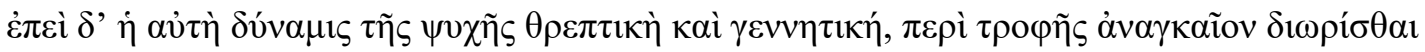

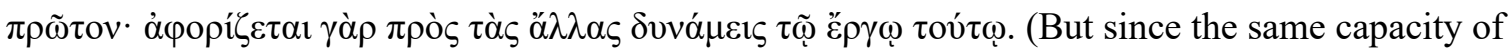
soul is nutritive and reproductive, first it is necessary to make determinations about nutrition, for [this capacity] is distinguished from the other capacities by this function.)

This indicates that Aristotle views the account of nutrition as particularly important for understanding why the nutritive and reproductive functions comprise a single capacity of soul. He reiterates the need to begin by making determinations about the nutritive function in much the same terms as he has before

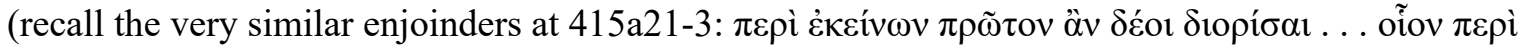

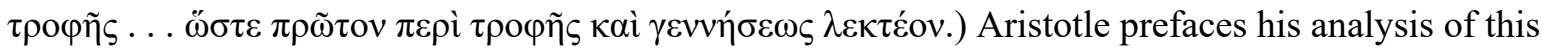


function with an aporia regarding the status of the nutrients: is food like or unlike the thing fed (416a21b9)? Aristotle's answer to the aporia is designed to highlight the assimilative character of nutrition: it takes unlike material and makes it like that which is fed. Nothing about this discussion, however, indicates anything definitive about Aristotle's view on the antikeimenon of the nutritive capacity. ${ }^{24}$ Rather, the point of the passage is to show where causal responsibility lies for the process of nutrition: it is the thing fed which acts upon the food and so is responsible for assimilation, not vice versa (416a34b3). ${ }^{25}$ After Aristotle has solved the aporia, he turns in earnest to an analysis of the assimilative function of nutrition. Here, we suggest, is where he finally identifies the antikeimenon of the nutritive capacity (DA 2.4, 416b9-11):

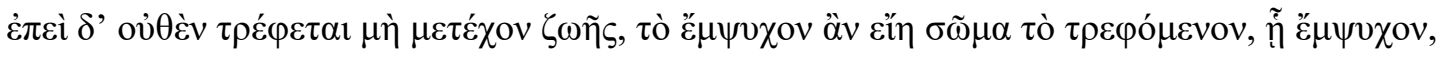

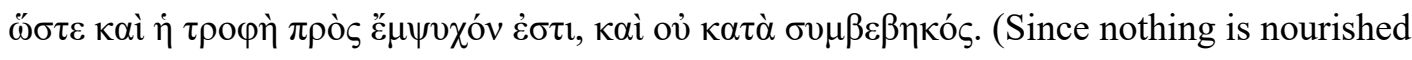
which does not participate in life, that which is nourished would be the ensouled body insofar as it is ensouled; and so nutrition is relative to the ensouled, and not in an incidental way.)

Following the standard interpretation, translators typically render trophē in this sentence as 'food' or 'nutrients', and commentators read this as a claim about the relation between the antikeimenon 'nutrients' and the organism qua capable of nutrition: nutrients have a non-incidental (i.e. per se) relation to the ensouled organism. But Shields notes that the claim, taken in this way, poses a problem vis-à-vis the DPP: the DPP asserts that antikeimena are prior in account to activities and capacities, but here Aristotle seems to assert that 'food can be characterized only with reference to (or relative to: pros, 416b11) an ensouled body - that is, a body with at least a nutritive soul' (Shields 2016, 208). Shields worries that Aristotle's insistence on the per se character of that relation thus gives rise to a 'methodological circularity'. We can put the worry in even stronger terms than Shields does. On the standard reading, $D A$ 2.4, 416b9-11 states that the antikeimenon, nutrients, has a per se relation to the capacity, nutritive soul (or to the organism qua having this capacity). But, as we have seen in Section 3, per se relatives are account-dependent on their correlatives (Top. 6.4, 142a26-31). Therefore, on this reading, the antikeimenon, nutrients, is account-dependent on the capacity. But DPP insists on account priority for antikeimena. Thus, there is a contradiction.

\footnotetext{
${ }^{24}$ As noted earlier, the word $\alpha v \tau \iota \kappa \varepsilon i ́ \mu \varepsilon v o v$ does appear at 416a34, but clearly is used there to mean the terminus ad quem of a change rather than the object of a capacity.

25 The discussion thus serves to distinguish the causality involved in nutrition from that of perception and thought; for the latter two, Aristotle emphasizes that the cause is external and distinct from that which perceives or thinks (Cat. 7, 7b15-8a12; Metaph. Г.5, 1010b30-1011a2).
} 
In light of this problem posed by the standard reading of $D A 2.4,416 \mathrm{~b} 9-11$, we suggest an alternative interpretation which eliminates the problem. Rather than assume that these lines claim the antikeimenon 'nutrients' has a per se relation to the capacity of nutritive soul, we suggest they claim that the capacity (or activity) of nutrition has a per se relation to its object: the ensouled body qua ensouled. Our interpretation thus reads these lines as stating that the ensouled body qua ensouled is the correlative object of the nutritive capacity. All that our interpretation requires is that one read the word 'trophe' in the passage as 'nutrition' rather than assume it must mean 'nutrients'. Granted, Aristotle does not use the word 'antikeimenon' here. Our interpretation is possible nevertheless, for Aristotle often indicates the object correlative to a capacity simply by saying that $x$ (capacity) is pros $y$ (as we have seen in the Categories and Metaphysics; cf. similar usage at DA 2.6, 418a24-5 and 3.4, 429a17-18). Our way of interpreting $416 \mathrm{~b} 9-11$ is preferable to the standard reading for three reasons. First, on the standard reading, the lines would contravene Aristotle's own subtle position regarding the asymmetry of soulobject relations. In Aristotle's discussions of relatives from the Categories, Topics and Metaphysics, he insists that capacities have a per se relation to their objects, but that these objects do not have a per se relation to their capacities. On the standard reading of 416b9-11, the lines say that nutrients (taken as the antikeimenon) do have a per se relation to the capacity, and so would clash with Aristotle's own stated position on soul-object relations. On our reading, however, the lines harmonize with his account of such relations: now they claim instead that the capacity has a per se relation to its antikeimenon. Second, on the standard reading, Shields' worry about a 'methodological circularity' obtains; on our reading, there is no circularity or contradiction. If the nutritive capacity has a per se relation to its object, then that capacity must be account-dependent on its object, which is exactly what DPP stipulates. ${ }^{26}$ Third, on our reading, the lines figure directly into a larger account that explains why Aristotle insists on the unity of the nutritive and reproductive functions (which we argue for in the remainder of this article). The standard interpretation of nutritive soul, which assumes that nutrients are the antikeimenon of the nutritive capacity, lacks such an account, for it is not clear how or why food would serve as the object of reproduction. To secure these three benefits, however, requires abandoning the assumption that the antikeimenon of the nutritive capacity is nutrients.

\footnotetext{
${ }^{26}$ By contrast, we should not assume that 'the ensouled body qua ensouled' is account-dependent on the capacity for nutrition, nor that it should have a per se relation to that capacity. The 'most common account' of soul (and by extension the general account of the ensouled body) makes no reference to nutrition (cf. $D A$ 2.1, 412a19-b6). So our position accommodates the asymmetry of soul-object relations. The general account of soul as developed in $D A 2.1-$ 3 must remain independent of the account of nutrition, for there are certain ensouled bodies that do not possess the capacity of nutrition (i.e. the heavenly bodies, including the stars, planets and the sphere of the outer heavens; see e.g. De Caelo 2.2, 285a27-30; 2.3, 286a7-12; 2.12, 292a14-293a14; and Johansen 2009, 18-27).
} 
So far, we have seen how two important passages regarding the object of nutrition, 415a20-2 and 416b9-11, are problematic on the standard interpretation and are ameliorated by our own. Our interpretation stipulates that nutrients are not the antikeimenon of nutrition. If this is so, then how exactly does Aristotle understand the role of nutrients vis-à-vis his analysis of this capacity and its object? At the end of $D A 2.4$, Aristotle offers a tripartite distinction that lays out in clear terms the concepts at play in the operation of nutrition (DA 2.4, 416b20-3):

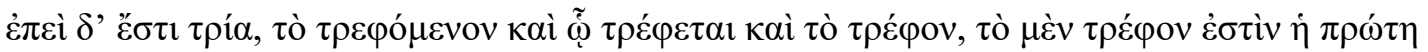

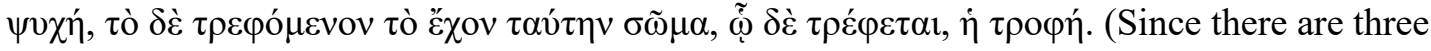
things - that which is nourished, that by means of which it is nourished, and that which nourishes - that which nourishes is the first soul, that which is nourished is the body having this [first soul], and that by means of which it is nourished are nutrients.)

The third term, to trephon, specifies the capacity (the 'first soul', i.e. nutritive soul): 'that which does the nourishing' is nutritive soul in its proper activity. The first term, to trephomenon, specifies the corresponding object of this activity: 'that which is nourished' is 'the body having this [first soul]' (a gloss on 416b9-10, where he claims that to trephomenon is 'the ensouled body insofar as it is ensouled'). Aristotle thus eloquently captures the soul-object relation with corresponding active and passive participles: the object of to trephon, that which nourishes, is to trephomenon, that which is nourished. Nutrients occupy a different category: they are 'that by means of which' the object of nutrition is nourished. The instrumental dative in $\tilde{\omega} \delta \varepsilon \dot{\varepsilon} \tau \rho \varepsilon ́ \varphi \varepsilon \tau \alpha \iota$ expresses the conditions necessary for nourishing to take place (DA 2.4, 416b25-9):

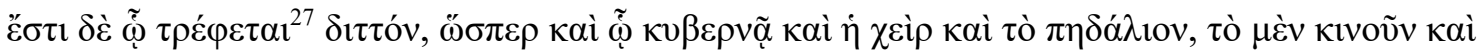

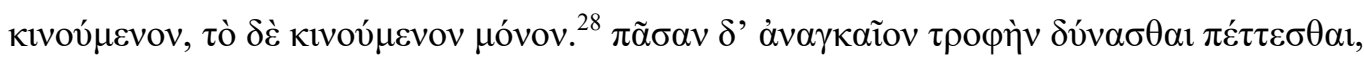

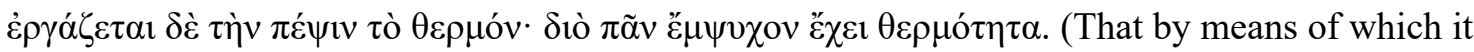
is nourished is twofold, just like 'that by means of which it steers' is: both the hand and the rudder [are that by means of which one steers], in the first case [it is] that which both moves and is moved, in the second case [it is] that which is moved only. It is necessary for all nutrients to be able to be concocted; heat activates concoction; therefore, all ensouled things have heat.)

\footnotetext{
${ }^{27}$ Ross reads $\tau \rho \varepsilon ́ \varphi \varepsilon ı$ in 416b25-6; we read $\tau \rho \varepsilon ́ \varphi \varepsilon \tau \alpha 1$ with other mss. Pace Ross 1961, 231-2, even if one reads $\tau \rho \varepsilon ́ \varphi \varepsilon 1$ here, the referent of the phrase is the same, for that by means of which nutritive soul nourishes (in the active) is identical to that by means of which the thing nourished is nourished (in the passive), i.e. nutrients and heat.

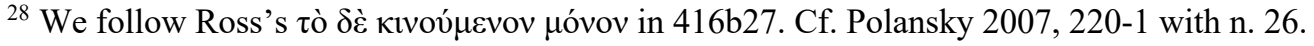


Coxswains move their hands, which in turn move the rudder, so that the hand is itself moved while also being responsible for the motion of the rudder. The rudder, by contrast, is 'moved only'. Similarly, heat is 'moved' in the sense of being generated and regulated by the organism, and 'moves' in the sense that it is responsible for the concoction of nutrients. Nutrients, like the rudder, are 'moved only', for they are made to undergo the process of concoction and assimilation. ${ }^{29}$ Both the hand and the rudder are necessary for the navigation of the boat: if navigation is to take place, coxswains must use their hands to steer the rudder. Likewise, Aristotle suggests, both heat and nutrients are necessary for the nutrition of the organism: if nutrition is to take place, the organism must use heat to concoct nutrients. Both heat and nutrients thus play a vital causal role in the activity of nutrition without thereby being fully explanatory of

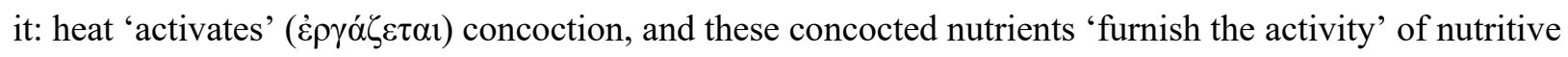

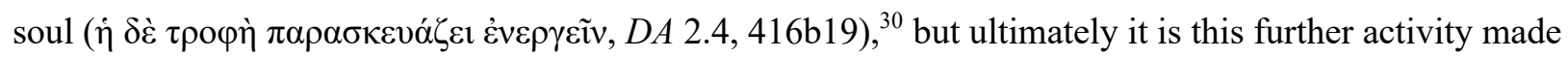
possible by heat's concoction of nutrients that constitutes nutrition. Given this subordinate causalexplanatory role, Aristotle dubs them sunaitia, 'contributing causes' of the activity of nutrition, and insists that the role of proper cause be reserved for the soul. ${ }^{31}$ Neither heat nor nutrients are themselves the antikeimenon of nutrition, but are rather necessary conditions of this capacity of soul being actively engaged with its antikeimenon: they are that by means of which the capacity nourishes its object. Despite not serving as the antikeimenon of nutritive soul, nutrients thus have a well-defined causal role in the activity of nutrition. ${ }^{32}$

${ }^{29}$ Cf. DA 2.4, 416a34-b3: just as the carpenter acts on their materials (and not vice versa), that which is nourished acts on the food (and not vice versa).

${ }^{30} \pi \alpha \rho \alpha \sigma \kappa \varepsilon v \alpha \dot{\zeta} \omega$ with a complementary infinitive is not widely used in the corpus, but seems typically to be used by Aristotle to mean 'to produce', 'to cause' or 'to furnish' something's occurrence: see e.g. Poet. 4, 1449a15-18; Rhet. 2.11, 1388a34-7; 2.17, 1391a32-3.

${ }^{31}$ Cf. $D A$ 2.4, 416a9-18: some thinkers (the Heracliteans?) believe fire to be 'without qualification a cause' ( $\dot{\alpha} \pi \tilde{\omega} \varsigma$ aitía) of nutrition, for fire alone of bodies seems 'to be nourished' ( $\tau \rho \varepsilon \varphi$ ó $\mu \varepsilon v o v)$, so that one might suppose it is fire that is truly 'the thing at work' ( $\tau$ ò $\dot{\varepsilon} \rho \gamma \alpha \zeta$ ó $\mu \varepsilon v o v$ ) in nutrition; 'but while [fire] is in some way a sunaition, it is not a simple cause - rather, the soul is [the simple cause].' For nutrients and heat as necessary conditions for life, cf. $P A$ 1.1, 642a1-13 and 2.3, 650a2-8 and Lennox's notes ad loc.; cf. Metaph. $\Delta .5,1015 \mathrm{a} 20-2$ and b3-6; Protrepticus fr. B42 Düring. Menn recognizes that nutrients serve 'only as an instrument or necessary condition of the soul's activity of nourishing' $(2002,120)$, but he does not see the implications this has for the antikeimenon issue.

32 These considerations undermine the principal suggestion of the standard interpretation on how food serves as the antikeimenon of reproduction as well as nutrition. Consider Polansky's explanation of the unity of nutrition and reproduction: 'In fact these works overlap because reproduction depends upon using food. Reproduction fits within the nutritive capacity because the food that is employed for the growth and maintenance of the organism also becomes in its ultimate rendering the seed that serves for propagating new life' (Polansky 2007, 204; Johansen 2012, 107-9 makes much the same argument about the unity of the two functions). Of course, both functions also 'depend upon' the body's heat for this concoction; yet vital heat is certainly not the object of either. Showing that Aristotle understands both nutrients and heat as necessary conditions for nutrition thus speaks strongly against the standard 
Nevertheless, nutrients do serve as the antikeimenon for a different capacity of soul, namely, taste (as a modification of touch). In $D A 2.10-11$, Aristotle argues that taste is a kind of touch, for the object of taste is a tangible body, and the organ of taste (the tongue) must be in contact with the object in order to perceive it. Then in DA 3.12 he claims that taste is the perception of nutrients (434b18-24):

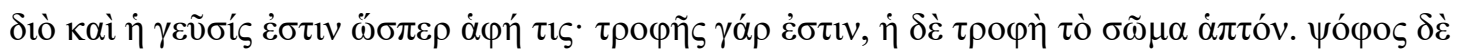

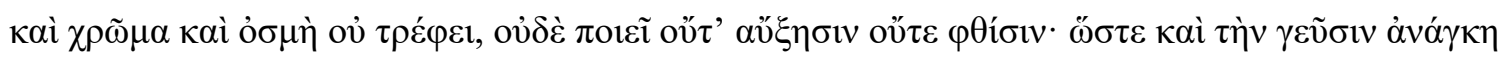

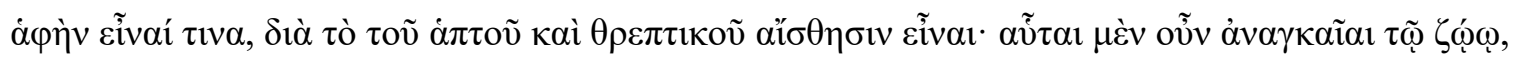

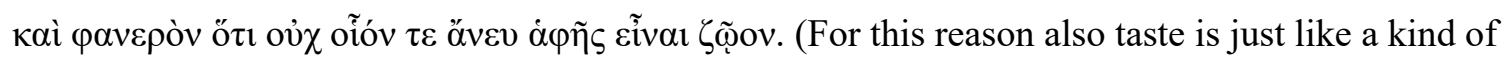
touch, for it is of nutrients, and nutrients are a tangible body. Sound, color, and smell do not nourish, and neither do they cause growth or diminution. So it is necessary that taste is a kind of touch, on account of [taste] being the perception of that which is tangible and nutritious. Then these [i.e. touch and taste] are necessities for the animal, and it is clear that without touch it is not possible for the animal to be.)

Taste perceives the nourishing features of bodies (i.e. their tasteable and tangible features); hence the object of taste is 'that which is tangible and nutritious' ( antikeimenon that corresponds to the capacity of taste, is nutrients. ${ }^{33}$ If, however, soul capacities are individuated by their antikeimena, ${ }^{34}$ the nutritive capacity should then have a correlative object distinct

interpretation of the antikeimenon of nutritive soul. Being a necessary condition of nutrition or reproduction is not sufficient for qualifying as the antikeimenon of either.

${ }^{33}$ This interpretation is confirmed by corresponding passages in De Sensu. De Sensu 4 explains the dual role that nutrients can serve in the activity of nutrition: the tangible features of nutrients are the cause of growth for animals, while the tasteable features of nutrients (namely, its sweet components) are the cause of nourishment (De Sensu 4, 441b23-442a8). Here he insists that the flavor perceived by taste does not belong to just any kind of tangible body, but specifically to the object proper to this capacity: nutrients. And again, Aristotle reiterates that nutrients play the role of instrumental cause in the activity of nutrition, similar to heat: just as heat is responsible for 'working up' the nutrients consumed (by separating out the nutritious, sweet material from the bitter and salty components of food) so

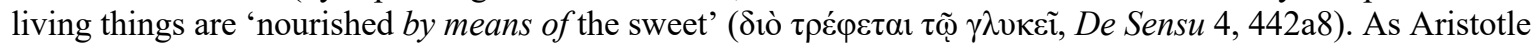
emphasizes at the opening of De Sensu, the function of taste is to detect the presence (or absence) of such nutritious material within the tasteable, allowing this presence (or absence) to be signaled by pleasure (or pain) so that the tasted object can be pursued (or avoided) (De Sensu 1, 436b10-18). Aristotle makes the same point in the very closing lines of $D A$ : animals have taste 'on account of pleasure and pain, in order that they may perceive that which

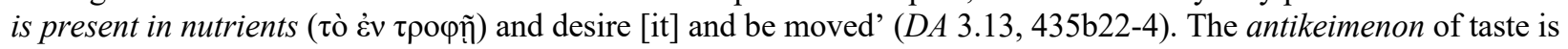
nutrients, and animals possess this sense in order that they might detect the nutritious materials within whatever they taste and subsequently desire and pursue them, for the sake of their nutrition and growth. Taste thus forms part of the basic perceptual apparatus that belong to all animals, for it is the capacity by means of which animals perceive the nutrients that are required for them to survive (De Sensu 1, 436b12-14; cf. DA 3.12, 434b22-4).

${ }^{34}$ Cf. Johansen 2012, 94 and 106. 
from that of taste. This analysis of taste thus provides corroborating evidence for our rejection of the standard interpretation regarding the antikeimenon of the nutritive capacity.

\section{The Ensouled Body qua Ensouled as the antikeimenon of Nutrition}

We have seen Aristotle indicate that to trephon, that which does the nourishing (i.e. the nutritive capacity), corresponds to to trephomenon, that which is nourished (i.e. the ensouled body insofar as it is ensouled). The activity of nutrition is the nourishing of the ensouled body, as the activity of sight is the perception of the visible body, the activity of taste is perception of the tasteable body, etc. What then does it mean that the object of nutrition is 'the ensouled body insofar as it is ensouled'? After Aristotle identifies the ensouled body as the object of nutrition, he immediately goes on to explain how this capacity engages with its object ( $D A 2.4,416 \mathrm{~b} 11-20)$ :

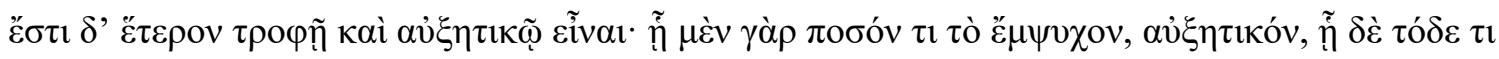

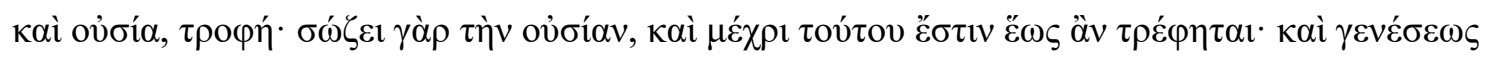

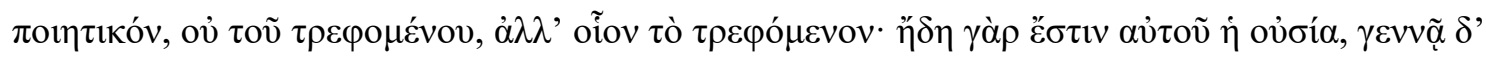

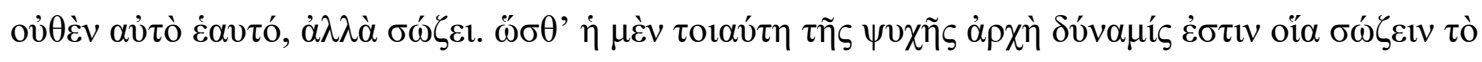

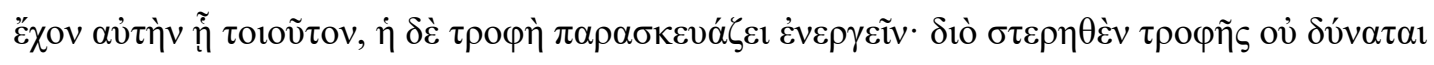
Eiv $\alpha 1$. (Being nutrition is different from being growth-promoting. For insofar as the ensouled thing is a certain quantity, [this capacity] ${ }^{35}$ is growth-promoting, but insofar as the ensouled thing is a this and a substantial being, [this capacity] is nutrition. For [this capacity] preserves the substantial being, and [the substantial being] is for just so long as it is nourished. And [this capacity] is productive of generation, not of the thing nourished, but of one like the thing nourished; for the substantial being of this [i.e. of the thing nourished] already is, and nothing itself begets itself, but it does preserve itself. Hence this sort of principle of the soul is a capacity such as to preserve the thing having this capacity as such, and the nutrients furnish the activity [of the capacity]. Accordingly, when deprived of nutrients, [a living thing] cannot be. $)^{36}$

\footnotetext{
${ }^{35}$ In the Greek, the reader is left to supply a subject here. Translators operating with the standard interpretation of $D A 2.4$ usually supply a vague subject; e.g. Shields 2016 supplies 'something', Sachs 2004 supplies 'what is added'. But the context strongly indicates the implied subject is $\dot{\eta} \alpha v i \tau \dot{~ \delta v ́ v \alpha \mu \iota \varsigma ~} \tau \tilde{\eta} \varsigma \psi v \chi \tilde{\eta} \varsigma$ from 416a19, and the subsequent text confirms this. Aristotle makes the subject he has been discussing in these lines explicit at 416b17-18: $\dot{\eta} \mu \dot{\varepsilon} v$

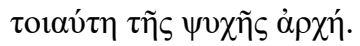

${ }^{36}$ We mark existential uses of the verb Eivval here with italics as a translation convention and for emphasis.
} 
As usual, the word trophe is typically translated throughout this passage as 'food' or the like. But translating it as 'nutrition', in accordance with our argument above, provides a much more natural initial distinction between two different, albeit related, functions: nutrition and growth. ${ }^{37}$ That distinction is more appropriate given the immediately preceding context, in which Aristotle has insisted upon making the necessary distinctions concerning the various functions of 'the same capacity' of nutritive soul ( $D A$ 2.4, 416a19-20). Having just identified the ensouled body qua ensouled as the object of the capacity, Aristotle now illustrates how the three functions of nutritive soul (growth, nutrition and reproduction) relate to this object.

Insofar as the ensouled body is a quantity, nutritive soul can augment the organism. The growthpromoting function of nutritive soul is thus a derivative function, for while it does have the ensouled body as its object, it is only insofar as this ensouled body is a quantity. Nutrition, by contrast, engages with the ensouled body precisely qua ensouled, i.e. insofar as it is an ousia. Nutritive soul 'preserves' or 'saves' ( $\sigma \omega ́ \zeta \varepsilon i v)$ the ensouled body as an ousia, which continues to exist as long as it participates in nutritive selfpreservation. Aristotle highlights the fact that this process is not a continual self-generation: rather, it is the way an organism maintains its own being. ${ }^{38}$ In his causal analysis of the soul earlier in $D A 2.4$, Aristotle has argued that the soul is the ousia of the ensouled body, for it is the cause and principle of the being of the living body. ${ }^{39}$ The soul is the ousia of the ensouled body by virtue of being the form of this body: 'it is necessary then that the soul is ousia as form of a natural body having life in potentiality' (DA 2.1, 412a19-21). If the soul is the substantial being of the ensouled body as its form, and this form is the cause and principle of the being of the ensouled body ( $D A 2.4,415 \mathrm{~b} 12-14)$, then the organism's continued being, its life, depends precisely on maintaining its form: 'Hence this sort of principle of the soul [i.e. nutritive soul] is a capacity such as to preserve the thing having this capacity as such.' Nutritive soul is the capacity to preserve the organism possessing nutritive soul 'as such', i.e. as the very kind of thing which it is (as a cat, as a human being, as an oak tree, etc. ${ }^{40}$ Because it is the form which makes the

${ }^{37}$ Cf. Polansky 2007, 216 n. 20.

${ }^{38}$ As we discuss below, Aristotle may be thinking of Symp. 207d4-e2 here.

${ }^{39} \mathrm{Cf}$. DA 2.4, 415b8-14: one of the three ways in which the soul is cause and principle is 'as the substantial being of

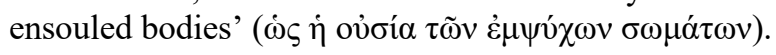

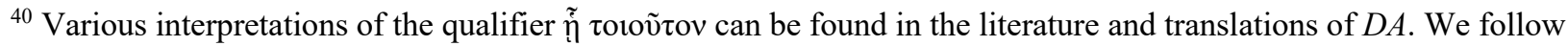
Polansky, Sachs, Shiffman and Shields by interpreting it to mean 'as the kind of thing it is' (i.e. in its essential identity as a cat, human being, or oak tree; cf. Polansky 2007, 217; Sachs, Shiffman and Shields translate accordingly ad loc.). It could instead have the narrower meaning 'as having nutritive soul'. On this narrower reading, the claim would be that the nutritive capacity is such as to preserve the living thing insofar as it has this specific capacity, nutritive soul. Even on this narrow reading, though, the total functional identity of the organism is implicated in its ability to preserve nutritive soul, for all the other functions of an animal or human being (perceptive, locomotive, or intellective) depend, at least in part, on the organism's ability to maintain the organs necessary for the activity of those capacities. As our subsequent analysis reveals, the nutritive activity is responsible 
composite be what it is, the capacity which nourishes (and thus preserves) the ensouled body must nourish (and thus preserve) the substantial being of this ensouled body: its form. As Aristotle puts it elsewhere: 'that which is nourished is the shape and form having been taken together with the matter' (

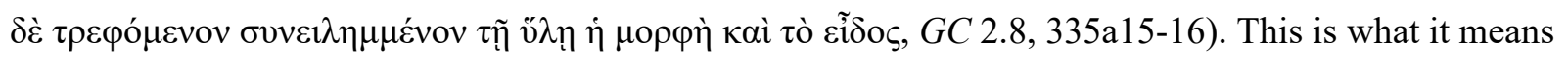
for the object of nutrition to be the ensouled body qua ensouled: nutrition nourishes, and thus preserves, the form-in-the-matter. Aristotle concludes the $D A 2.4$ passage by distinguishing (with a men . . de ... construction) trophe as the capacity of nutrition from trophe as the nutrients required for this capacity to become active: on the one hand, trophe as 'nutrition' is a capacity to preserve that which has it as such; on the other hand, trophe as 'nutrients' are what furnish the materials for the activity of this capacity, and so are a necessary condition, a sunaition, for the continued being of the organism (for if the living thing 'is for just so long as it is nourished', but 'nutrients furnish the activity' of nourishing, then 'when deprived of nutrients, [a living thing] cannot $b e^{\prime}$ ). Aristotle thus takes pains to carefully distinguish the dual usages of the term trophe, and to clearly indicate the relationship between its two possible referents. Why does Aristotle insist that 'nothing generates itself', given that he has been arguing that nutrition and reproduction are functions of the same capacity? As Quarantotto has suggested, part of the explanation is the need to distinguish what he is saying from an apparently similar claim made by Plato at Symposium $207 \mathrm{c}-\mathrm{e} .{ }^{41}$ In that passage, Plato has Diotima discuss reproduction as a way that mortal can have a share in immortality - but she then goes on to say (Symp. 207d4-e2):

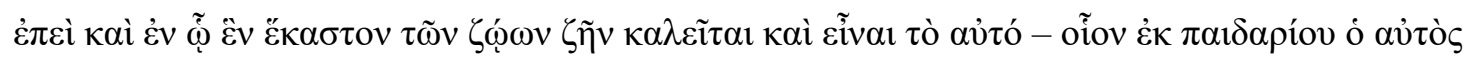

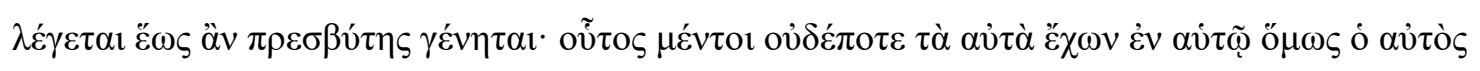

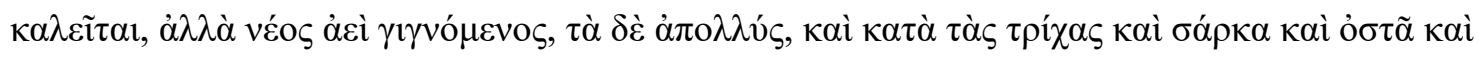

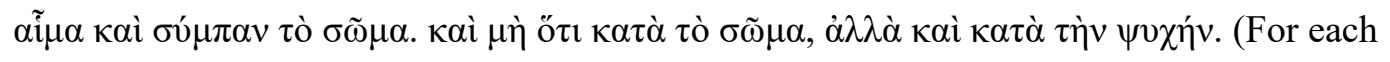
individual animal is said to be the same so long as it continues to live, like how the same man is

for maintaining the same overall functional relation of all parts of the body, and so maintains the living creature in its total functional identity, not merely qua nutritive (cf. Apostle 1981, 111 n. 31). A third popular option for

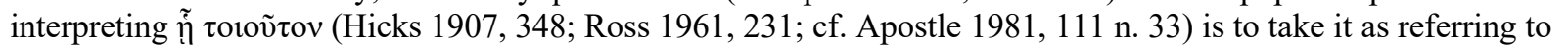
$\tau o ́ \delta \varepsilon \tau 1$ kaì ov̉oía in 416b13: Ross glosses the meaning of the phrase as 'it preserves the feeder's individuality' (although compare Ross 1961, 23: 'considered as a particular kind of substance it is fed, preserving therein its essential character'). While it is surely correct that nutrition preserves the individual organism, we suggest that it does so by preserving the principle and cause of the organism's being, namely, its form (hence the shift in usage of the term ousia at 416b16). For the form as the cause and as the substantial being of the individual, see Metaph. Z.17 (esp. 1041a32-b11, b25-33) which provides the background for Aristotle's claim in DA 2.4 that the soul is the cause of an organism as its ousia (415b12-14; cf. Shields 2016, 203-4).

${ }^{41}$ The idea that Aristotle's claim 'nothing generates itself' targets Diotima's characterization in the Symp. was argued by Quarantotto during a conference presentation in 2016 in Salt Lake City. The passage is further discussed in Quarantotto forthcoming. 
called the same from infancy until he becomes an old man. Yet for all we call him the same, he never has the same [parts] within himself, and he is always becoming new, because he keeps losing his parts, i.e. [losing] in respect of his hair, flesh, bones, blood and all the rest of his body. And not only in respect of his body, but also his soul.)

Aristotle is arguing that, to the contrary, the form of each of those uniform parts, and indeed of the ensouled body as a whole, is not in the constant process of becoming described in Diotima's speech, but is preserved as the being it is.

In $D A$ 2.4, Aristotle argues that the object of nutritive soul is the ensouled body insofar as it is ensouled. The activity of nutrition engages with its object by preserving it, maintaining the ensouled thing as precisely the kind of thing it essentially is. ${ }^{42}$ The metaphysical analysis of nutrition in $D A$ is thus concerned with nutrition's role in preserving the form of living things. A problem might seem to arise, however, when we compare the argument of $D A 2.4$ to Aristotle's physiological analysis of nutrition in $P A$. There Aristotle suggests that nutrition is actually concerned with the preservation of the living body's uniform parts (flesh, bone, fat etc.) and (indirectly) its instrumental parts. This asymmetry, however, is only apparent: the analysis of nutrition in $P A$ is designed precisely to provide a thoroughgoing physiological explanation for how nutritive soul accomplishes the preservation of the ensouled body. It is, as it were, where the ontological rubber hits the biological road: Aristotle needs to explain how the maintenance of the structural unity of the body, through a constant influx and assimilation of new material, allows the organism to preserve its characteristic life capacities, i.e. its form. ${ }^{43}$ Because these characteristic life capacities are ultimately dependent on complex interrelations between the fundamental material powers of the body's uniform parts, the maintenance of those uniform parts through nutrition is how the soul preserves the living thing's total functional identity (i.e. how it preserves the organism's form). ${ }^{44}$

${ }^{42}$ Aristotle also carefully distinguishes the preservative function of nutrition from the generative function of reproduction here, while simultaneously highlighting how both share the same correlative object. This will be discussed in detail in the following section of the paper.

${ }^{43}$ Aristotle alludes several times in $D A$ to the role of nutritive soul in preserving the structural unity of the body. The soul, and specifically 'the cause of growth and being nourished', is what is responsible for 'holding the body together', preventing its dissolution and 'making [its elemental parts] into one thing' (DA 1.5, 410b10-13; 411b5-9, $15-17 ; 2.4,416 a 6-9)$.

${ }^{44}$ In the background of these discussions in $P A$ is Aristotle's argument in $G C 1.5$ that what is preserved and what grows in the process of natural growth is form, not matter. The proper subject of growth is the substantial being (ousia) whose functional identity (ergon) is preserved throughout the change (GC 1.5, 321a29-b2). Though the matter of the uniform parts of the body is always changing, the form of flesh, bone, etc. persists and is preserved (GC 1.5, 321b16-28). Aristotle's understanding of the function of blood in $P A$ clearly presupposes this account of the maintenance of the uniform parts - it explains why blood needs to be continuously produced and channeled throughout the whole body to each of its parts in order to renew them (cf. $P A 3.5,668$ a1-11 and our analysis below). 
In $P A$ 2.1, when discussing the relation between different levels of material composition within animal bodies, Aristotle explains the teleological priority of the non-uniform parts of the body over the uniform parts ( $P A$ 2.1, 646b10-27, trans. Lennox):

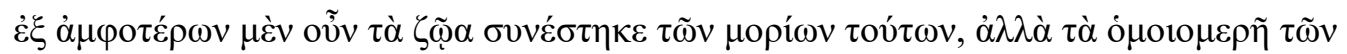

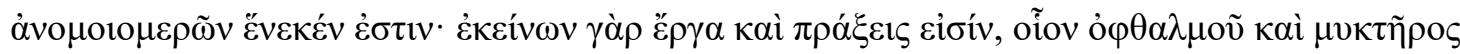

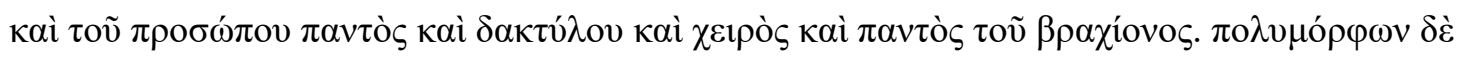

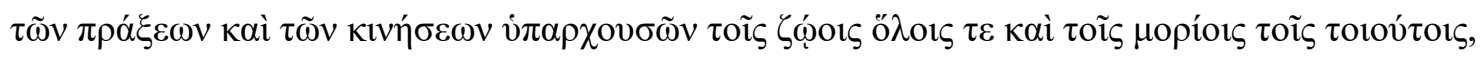

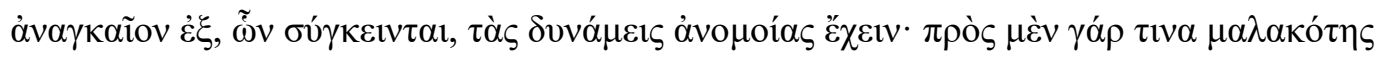

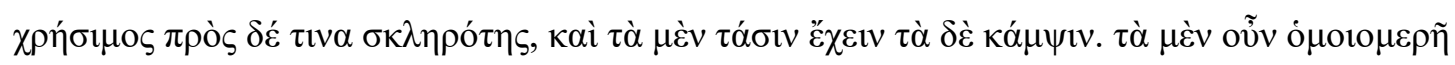

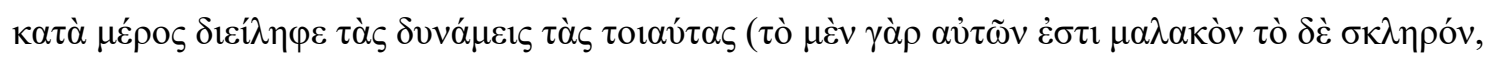

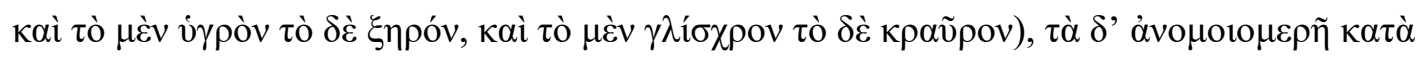

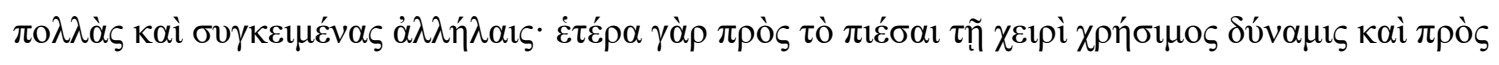

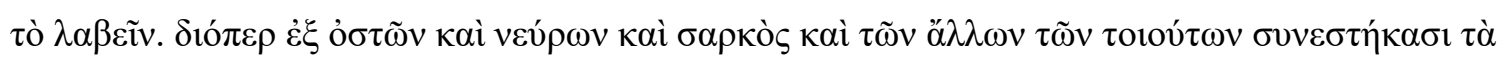

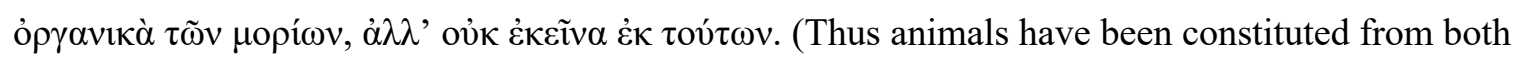
of these parts [i.e. uniform and non-uniform], but the uniform parts are for the sake of the nonuniform; for of the latter there are functions and actions, e.g. of eye, nostril, and the entire face, of finger, hand, and the entire arm. And since the actions and movements present both in animals as a whole and in their non-uniform parts are complex, it is necessary for their components to have distinct potentials; for softness is useful for some things, hardness for others; certain things must have elasticity, others flexibility. Thus while in the uniform parts such potentials are distributed part by part (one of them is soft while another is hard, one moist, another dry, one pliant, another brittle), in the non-uniform parts they are distributed to many and are conjoined with each other; for a different potential is useful to the hand for pressing and grasping. Accordingly, the instrumental parts have been constituted from bones, sinews, flesh, and other such parts, not the latter from the former.)

The activities of the non-uniform (i.e. instrumental) parts of the body, as well as the activities of 'animals as a whole' (i.e. activities that involve the operation of multiple instrumental parts in conjunction) are 'complex' (polumorphos) in the sense that they involve opposite and coordinated potentials of different

While we do not have the space here to analyze the important arguments from GC 1.5 in greater depth, extensive treatments can be found in Code 2004 and Kupreeva 2005. 
kinds of uniform parts. ${ }^{45}$ The movement of a cheetah's leg, as well as the movement of the cheetah as a whole, requires the coordinated interaction of different muscles, bones, tendons and cartilages. Some of these uniform parts must be soft and flexible while the others must be hard and rigid, all to different determinate degrees depending on their specific role in a given kind of motion or activity. Aristotle argues on this basis that the potentials of the uniform parts are necessary for both the activities of the individual instrumental parts and for the composite activities of multiple instrumental parts working in conjunction. Thus the non-uniform parts are teleologically prior to the uniform: the functions of the instrumental parts determine which uniform parts must be present, not vice versa. But part and parcel of this teleological relationship is the fact that the higher-level instrumental capacities of these organs are inoperable without the correct uniform parts present in the correct (healthy) condition, and in their proper relationships with one another. An organism's functional capacity to carry out its characteristic life activities is dependent on the integrity of the non-uniform parts of the body on which such capacities rely, which parts are in turn dependent on the integrity of the uniform parts from which they are composed.

But it is precisely the complex functions (erga), actions (praxeis), and movements (kinēseis) of 'animals as a whole' that comprise their characteristic ways of life (bios), and thus their overall functional identity. What makes a Galápagos finch different in kind from a Galápagos penguin just is the fundamentally different kinds of capacities (and thus different kinds of organs) that each possesses for their way of life (bios) in their particular kind of environment. ${ }^{46}$ Because the overall functional identity of an organism depends in this way on its uniform and non-uniform parts, we suggest that the preservation of the structural unity of the body (i.e. the maintenance of the integrity of all the body's uniform and nonuniform parts throughout their daily wear and tear) is precisely how living things preserve their overall functional unity.

$P A 3.5$ identifies the preservation of the uniform parts as the final stage in the process of nutrition. Aristotle has previously argued that blood is present in animals for the sake of the nourishment of their parts, and claims that blood is the 'final nourishment', i.e. the last stage of refinement and concoction which the consumed material undergoes before it becomes one of the uniform parts or one of the useful residues (semen, menstrual fluid etc.; cf. $P A$ 2.3, 650a15-b12 and Lennox' commentary ad loc.). The final stage in the process of nutrition is to channel the blood throughout the body in order to reconstitute the animal's parts ( $P A 3.5,668 \mathrm{a} 1-11$, trans. Lennox):

\footnotetext{
${ }^{45}$ Cf. Lennox' note ad loc.

${ }^{46}$ For more in-depth explorations on the connection between functional capacities, ways of life, and the essence of organisms, see Lennox 2001, 2010a, $2010 b$.
} 


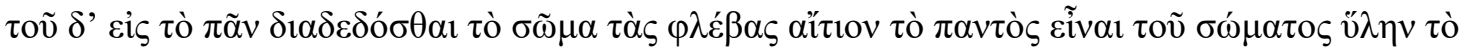

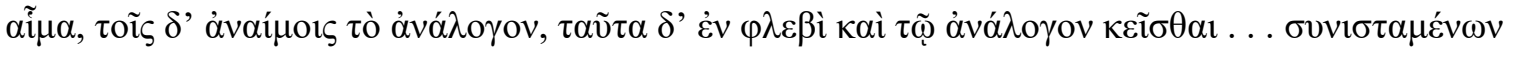

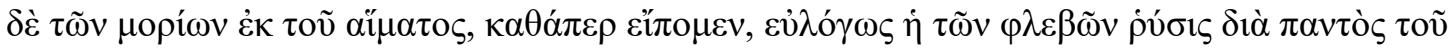

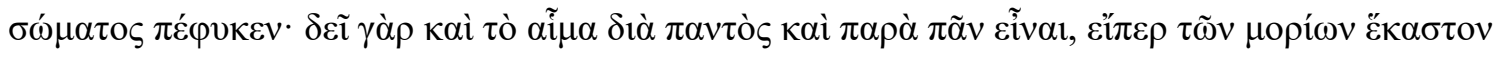

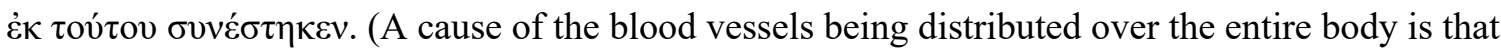
the blood and its analogue in bloodless animals are matter for the entire body, while these materials are stored in blood vessel and its analogue ... And since the parts are constituted from the blood, as we said, it is reasonable that the course of the blood vessels runs naturally through the entire body; for the blood too needs to be passing through everything and next to everything, if each of the parts is to be constituted from it. $)^{47}$

Thus, when the heart is no longer able to function, death ensues: 'for once the origin has been destroyed, there is nowhere from which aid might arise for the other parts that depend on it' ( $P A 3.4,667 \mathrm{a} 33-4$, trans. Lennox). Aristotle explains that the blood vessels are present even where they are not visible to the naked eye, and likens such vessels to irrigation channels that permeate the soil which they nourish ( $P A$ 3.5, 668a24-33, trans. Lennox):

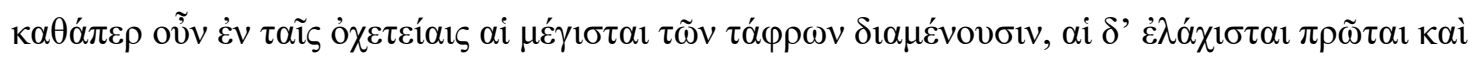

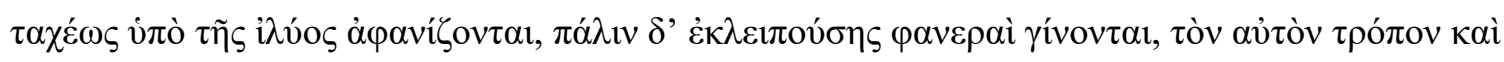

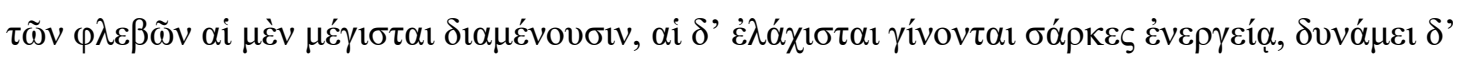

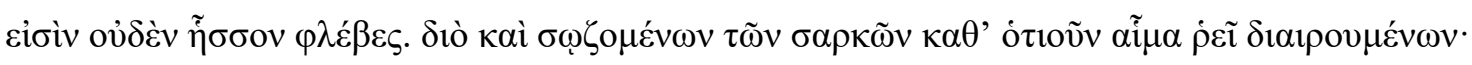

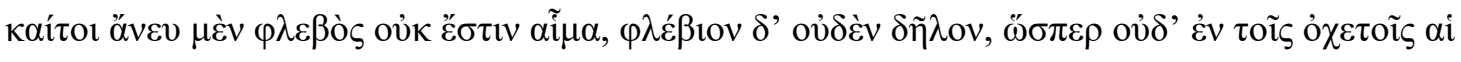

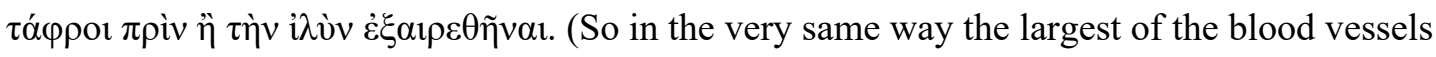
remain, while the smallest become in actuality flesh, though potentially they are blood vessels no less. For this reason too, when the flesh is in any way preserved, blood flows when it is cut; and though without blood vessel there is no blood, yet no blood vessel is manifest, just as in aqueducts the trenches are not manifest until the mud has been removed.)

If the uniform parts of the living body are not preserved in this way, the overall diminution of the organism ensues, and the blood vessels become visible again ( $P A 3.5,668 \mathrm{a} 19-22)$. The continual channeling of blood throughout the body preserves the flesh as actual flesh; by extension, it preserves the

\footnotetext{
${ }^{47}$ For blood as the matter of the body and as potentially any of the uniform parts, see $P A 2.4,651 \mathrm{a} 13-15 ; 3.5$, 668a17-19, 23-4; PN 474b3-5.
} 
organs which the flesh composes, and so also preserves the organism as a whole. ${ }^{48}$ As Aristotle puts it elsewhere, blood is the 'nourishment that provides being for both the whole and the parts' $(\theta \rho \varepsilon \pi \tau$ เ

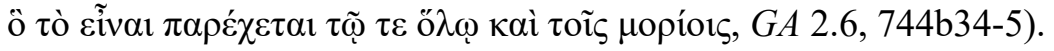

This account of cardiovascular physiology in $P A$ provides the biological details behind the

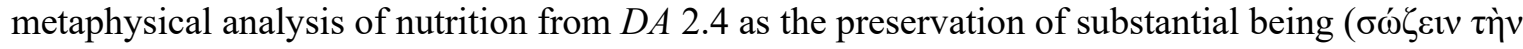

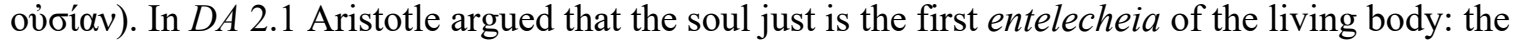
developed capacities of the body to perform the various activities characteristic of an organism's way of life. But one of those capacities, nutrition, has the function of preserving functionality, or functional identity, itself: thus, nutrition is the core capacity of soul, without which there can be no other capacity (as Aristotle often takes pains to highlight; e.g. $D A 3.12,434 \mathrm{a} 22-6)$. Hence nutrition, the capacity of soul directed at preserving this functional identity, has as its object the ensouled body precisely insofar as it is ensouled. Nutrition is fundamentally the capacity for self-preservation, or, as we will refer to it, for formal self-maintenance. The continual reconstitution of the uniform parts (which constitute the instrumental parts) is how the nutritive soul, as a principle of numerical unity and identity, is actualized biologically. ${ }^{49}$ That is, nutrition is how plants and animals continually reassert their own unity as ensouled bodies, how they persist as 'one in number'.

Armed with this new understanding of what it is to be an antikeimenon and of what the antikeimenon of the nutritive process is, we are prepared to resolve the puzzles which arise from Aristotle's insistence on the unity of the nutritive and reproductive functions.

\section{Reproduction as a Nutritive Function}

We began by characterizing two problems created by the fact that Aristotle distinguishes the preservative function of nutrition from the generative function of reproduction, while simultaneously insisting that 'the same capacity of the soul is nutritive and reproductive' ( $D A 2.4,416 \mathrm{a} 19)$. In addition to preserving the being of the ensouled body, qua ensouled, nutritive soul 'is productive of generation, not of the thing nourished, but of one like the thing nourished; for the substantial being of this [i.e. of the thing nourished] already $i s$, and nothing itself begets itself, but it does preserve itself' ( $D A 2.4,416 \mathrm{~b} 15-17)$. In insisting

${ }^{48} \mathrm{Cf}$. $P A$ 2.1, 647a35-b9, where he refers to this process of assimilation as like the continual depositing of silt along a riverbed: organs are like islands built up from the continuous accumulation.

${ }^{49}$ Our discussion of nutritive physiology has focused on blooded animals. Aristotle believes there is an analogous process occurring in bloodless animals ( $P A 4.4,678 \mathrm{a} 6-11$; 4.5, 678a27-b7). In $P A 2.3$, Aristotle provides a brief comparative physiology of plant and animal nutrition, focusing on their methods and organs for concoction $(P A 2.3$, 650a2-32; cf. PA 4.4, 678a6-15). Plant nutrition, it seems, is to be understood on much the same terms as animal nutrition, with the difference that it is the ground in which the plant grows that concocts the plant's nutrients rather than an internal source of heat. 
that organisms both preserve themselves and generate others like themselves, Aristotle is drawing our attention to the important philosophical reasons for distinguishing the nutritive capacity into two distinct, yet unified, functions. Let us now return to the opening argument in $D A 2.4$, which makes the case for reproduction (understood as formal self-maintenance) being the most natural of functions for complete living things, and to compare it with a passage in GA 2.1. Recently, Devin Henry has argued that these two passages are not concerned with the same topic. ${ }^{50}$ We insist that they are, and that key arguments in Metaphysics Z.8 reveal just how important understanding reproduction as formal self-maintenance is for Aristotle. Then we will return to another of our key passages from $D A 2.4$ (416b9-19) to show how all the pieces we have assembled fit together as an answer to Problem 1 (One antikeimenon or two?) Finally, we turn to a passage from $G A 2.4$ which confirms our interpretation, and provides an answer to Problem 2 (Why not 'reproductive soul'?)

We begin with a translation of the 'most natural' passage, broken into seven distinct points. Then we will build an interpretation by arguing for a reading of each that gives us a consistent understanding of the whole. $D A$ 2.4, 415a26-b7:

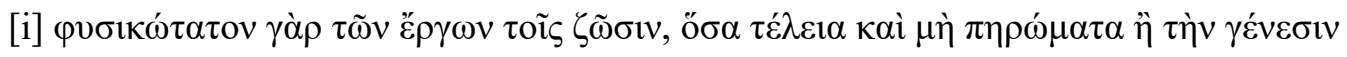

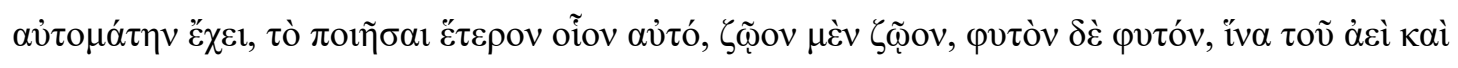

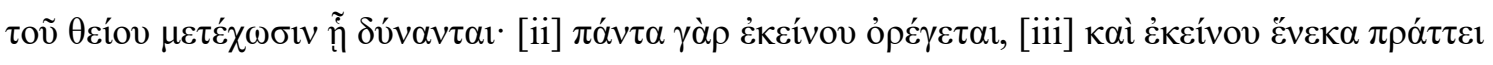

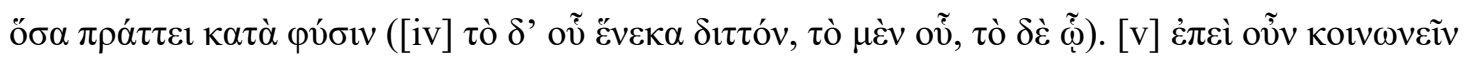

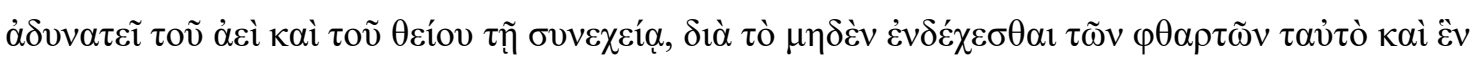

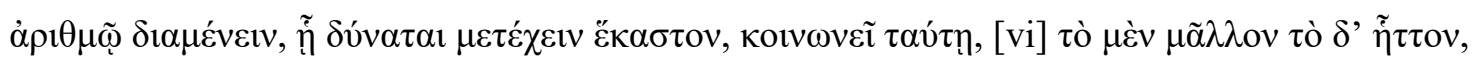

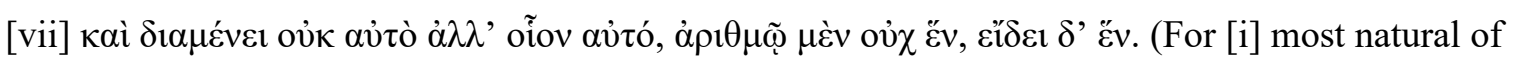
the functions in living things, as many as are complete and neither deformed nor generated spontaneously, is the production of another like itself, an animal an animal, a plant a plant, in order that they may participate, insofar as they are able, in the everlasting and the divine; for [ii] all [perfect living things] strive for this and [iii] do whatever they do in accordance with nature for the sake of this. (But [iv] that for the sake of which is double, the of which and the for which.) Now $[\mathrm{v}]$ since they are unable to participate in the everlasting and the divine continuously, on account of the fact that none of the perishable things admits of remaining the same and one in number, each one participates insofar as it is able, having a share in this way, [vi] some more and some less, and [vii] it remains not itself but like itself, not one in number but one in form.)

\footnotetext{
${ }^{50}$ Cf. Henry 2015 and 2019, Ch. 8.
} 
[i] The production of another being like itself is, Aristotle claims, the most natural of functions for 'complete' or 'perfected' ( $\tau \varepsilon \dot{\lambda} \varepsilon \varepsilon \alpha$ ) organisms. In Thomas Johansen's recent study of the De Anima, he addresses the question of why this is a most natural function $(2012,118-27)$. One reason why Aristotle might consider this function most natural, Johansen argues, is that it is the paradigmatic example of the soul serving as the nature of living things (Johansen 2012, 119). ${ }^{51}$ As we understand Johansen's argument for this claim, the nutritive soul is a paradigm nature in two different, if related, ways. First, it is in this capacity that the soul's role as inner principle of life is most clear; and, second, this is a capacity present universally in all mortal organisms for sustaining life. Our discussion in the previous section of Aristotle's detailed characterization of this process in $P A$ 2-3 underscores these points.

The way in which Aristotle supports the claim that reproduction is most natural among the ép $\gamma \alpha$ of living things corroborates this interpretation. In [i], he introduces the reader to two functions of the soul, but identifies only one of them as most natural, and that is the production of another like self. He then insists that this most natural of functions is performed by a perishable living being in order to partake of the everlasting and divine. ${ }^{52}$ [ii] and [iii] are introduced by a $\gamma \alpha \dot{\alpha} \rho$, and a natural way to understand that $\gamma \alpha \dot{\alpha} \rho$ is that it is introducing a further explication of the 'most natural' claim: participation in the everlasting and divine is what all (perfect) living things strive for, and they do whatever they do in

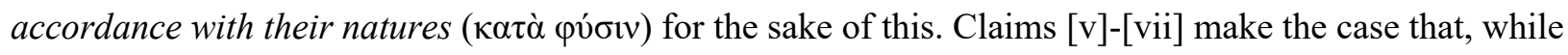
perishable living things are unable to maintain themselves as numerically one being forever, they are able to maintain themselves forever qua form, by producing another being like themselves in form. That is, we have the following argument:

1. Whatever complete/perfect living things do according to nature is done for the sake of partaking of the everlasting and divine.

2. Perishable living beings are unable to participate continuously in the everlasting and divine, i.e. they are unable, by means of nutritive activity, to maintain themselves as one in number forever.

\footnotetext{
${ }^{51}$ In saying this, he intends to tie the claim here back to the very opening lines of the $D A$, especially 402a4-6, where we are told that knowledge of the soul contributes greatly to the truth, and most of all to the truth about nature, since it is a principle of living things. However, it is important to note that in those opening lines Aristotle does not claim that the soul is a nature, and that may well be intentional: throughout $D A$, voũ is flagged as 'a different kind' of soul, as requiring a different account, as having no 'organ', and as in some manner separate. And $P A 1.1$ explicitly excludes its investigation from natural science and says it is not an inherent source of natural change. To capture the unity of the investigation of the soul, including voṽ s, Aristotle may be self-consciously down-playing the soul as a natural principle in the opening lines of DA 1.1, while in GA 2.4 (discussed below), which stresses that the nutritive / reproductive capacity is the nature of living things, qua living, it is appropriate to highlight the point.
}

52 Johansen 2012, 110 rightly notes the almost identical formulation of this idea at Symp. 207c8-d5; cf. Shields 2016, 201; Polansky 2007, 205. 
3. But they are able, to a greater or lesser extent, to participate in the everlasting and divine by reproducing, so that what remains, though not numerically one being, is formally one being.

What motivates this argument? One possible motivation derives from philosophical reflection on what unifies the many and varied activities on display in the living world. Careful observation of animals reveals that pretty much everything they do in accordance with their natures is done for the sake of selfpreservation - nothing else matters if an organism fails at that task. Whether by the use of their various senses to find food or to detect and avoid predators, or by their many and varied modes of locomotion (fleeing, stalking, hiding) activated and directed in response to information learned through perceptual activity, or by the physiological processes involved in converting the acquired nutrients into blood discussed in detail earlier in this paper, distributing that blood to the bodily tissues and organs and being taken up by those parts - everything they do seems to be directed to preserving their lives, to selfpreservation. Of course, it is of the nature of life that these efforts may fail, but continuity of being staying alive - does seem to be the goal of these activities.

The one (large) exception would appear to be activity devoted to reproduction. It has been a matter of constant debate in evolutionary biology why organisms expend so much time and energy on this - indeed certain organisms, such as the octopus we began with, seem to exist for no other reason. Aristotle's argument in DA 2.4 can be seen as an attempt to deal with this problem. Animals and plants are ensouled bodies. Living bodies composed of the four sublunar elements are perishable, and the capacities needed to maintain themselves gradually weaken. Every organism does what it does in the interests of self-preservation, but by the very nature of organic being, they inevitably die. Though numerically the same animal cannot live on forever, it can maintain its form by producing something one in form with it. Yet this form is the principle of its own life and being (DA 2.4, 415b12-14):

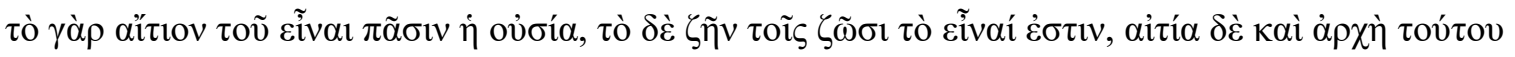
$\dot{\eta} \psi v \chi \eta \dot{~}$. (For in all cases the substantial being is the cause of being, while in the case of living things to be is to live, and the soul is the cause and principle of life.)

As such, reproduction allows the source and cause of being for the composite living thing, its soul, to live on. Recall Aristotle's emphasis in the 'most natural' passage above (at 415b3-7):

Now since they are unable to participate in the everlasting and the divine continuously, on account of the fact that none of the perishable things admits of remaining the same and one in

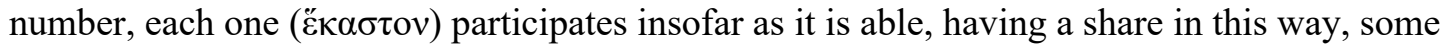


more and some less, and it remains ( $\delta 1 \alpha \mu \varepsilon ́ v \varepsilon \imath)$ not itself but like itself, not one in number but one in form.

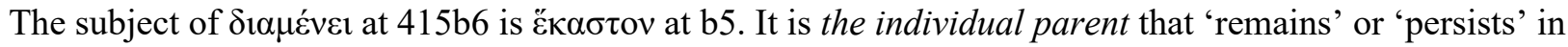
some way - albeit 'not itself' nor as 'one in number'. While plants and animals cannot be everlasting and divine (where 'divine' is a normative gloss on 'everlasting'), reproduction allows them to participate in what is everlasting and divine by persisting in the way that is possible for them. Each mortal organism can continue to be in form, but not in number. Seen in this light, the great effort expended upon successful reproduction is not an exception to the drive for self-preservation, but rather its culmination. Hence he says that everything done according to the nature of a living thing is done for the sake of partaking of the eternal and divine, and that this is what living things reach out or strive for. A passage at the beginning of the Politics helps us to understand why reproduction is a 'most natural' function of soul $(1.2,1252 \mathrm{a} 26-30)$ :

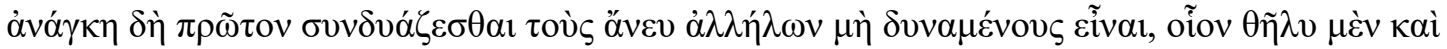

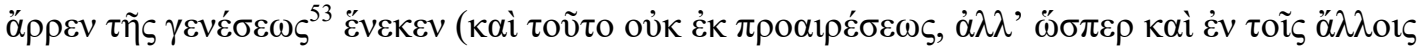

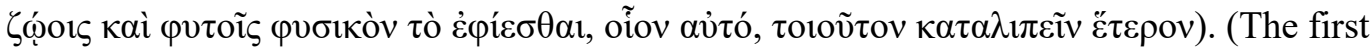
necessity is for the coupling of those that cannot exist without one another, i.e. of female and male for the sake of generation (and this [coupling] is not out of deliberative choice; rather, just as in the other animals and plants, the longing to leave behind another such as oneself is natural).)

This striving to procreate is not deliberative but natural. Aristotle has noticed, as biologists throughout history have, that a great deal of living activity is organized around the 'drive' to reproduce. And Aristotle thinks he sees the value achieved in doing so - it is a way in which a living thing may preserve its being, indeed, the source and cause of its being.

It is here, precisely, that another critical commonplace regarding the relation of the nutritive and reproductive functions goes wrong. Aristotle is not saying or implying that the goal is 'to reproduce the species' (Johansen 2012, 110); nor that 'living beings seek immortality by their participation in the eternal species via generation' (Shields 2016, 201). ${ }^{54}$ The species does not have existence independent of the

\footnotetext{
${ }^{53}$ Ross, following Stobaeus, reads $\gamma \varepsilon v v \eta ́ \sigma \varepsilon \omega \varsigma$. We are sticking with the reading found in all of the mss., although given the general confusion in the mss. regarding these words we do so without great conviction. Nothing much turns on the choice here.

${ }^{54}$ For representative expressions of this commonplace, see e.g. Aquinas, On the De Anima $\$ 317$ (Foster and Humphries 1951, 215); Apostle 1981, 108; Bodéüs 1993, 151 n. 6; Diamond 2015, 80; Freudenthal 1995, 36-40; Furth 1988, 160-1; Gill forthcoming; Hamlyn 1993, 95; Hicks 1907, 339-40; Johansen 2012, 110; Matthen 2009,
} 
particulars which exemplify it. There is only anything like the species 'octopus' in virtue of the existence of particular octopuses, and octopuses continue to exit in a potentially infinite line of generation due to wholly immanent efficient and final causes. To say that our mother octopus' sacrifice is somehow for the sake of the species as a whole thus gets the order of ontological and causal priority backwards. Indeed, Aristotle thinks it is precisely his metaphysics of reproduction which obviates the need for separate Forms (Metaph. Z.8, 1033b26-32):

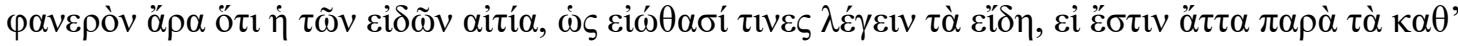

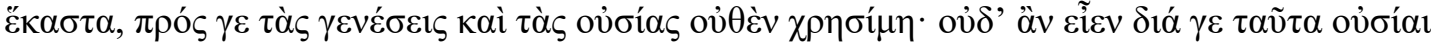

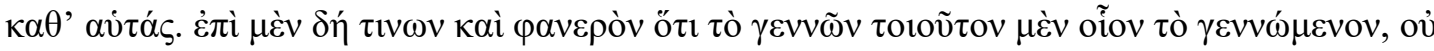

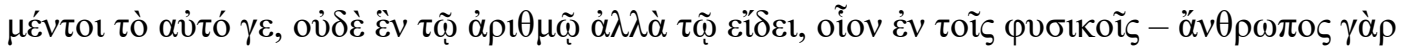

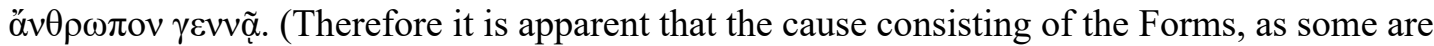
accustomed to discuss the Forms, supposing some things besides the particulars, are useless in relation to both generations and beings; nor should they on this account be substantial beings in themselves. Indeed, in some cases it is in fact apparent that the reproducer is such as that which is reproduced, not the same nor one in number with it, but one in form, as in natural things (for a human being reproduces a human being).)

And the chapter summary underlines the point (Metaph. Z.8, 1034a2-5):

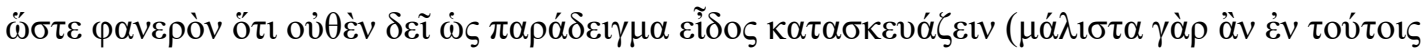

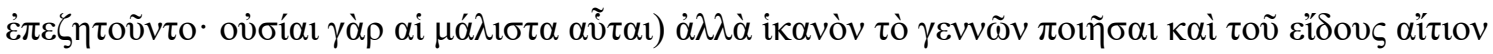

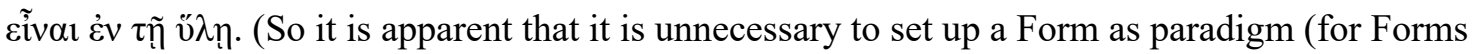
might have been sought most of all in these cases [i.e. in the cases of natural, living things]; for these are most of all substantial beings), but the parent is sufficient to produce and be the cause of the form in the matter.)

To treat the species 'octopus' as if it were something distinct from individuals with its own causal efficacy is to fall back into the snares of Platonism which Aristotle's ontology is designed to escape. The species cannot serve as the final cause of reproduction. Rather, the goal of the nutritive soul is continued being for the being that is reproducing - in part by preserving the form of the living body by delivering

344-5; Matthews 1992, 193; Menn 2002, 113; Nussbaum 1978, 77; Peck 1942, xlii; Preus 1975, 106; Shields 2016, 201. 
nutrients to all its tissues and organs (as discussed in the previous section), and in part by reproducing its form. Everything they do in accordance with nature is for the sake of self-preservation. ${ }^{55}$ They do not strive to preserve the species, nor is the continued existence of the species the means by which they seek immortality. ${ }^{56}$ The end for which they strive is their own continued being; the means for achieving this is reproducing something like them in form. Form, i.e. soul, is the source and cause of being for living things - when an organism's form is maintained, the individual's being is preserved. And Aristotle challenges us to think of reproduction in these same terms.

A passage near the beginning of GA 2.1 confirms this interpretation and provides additional metaphysical underpinning for Aristotle's argument. The passage, 731b22-732a1, is part of an argument for why the male and female principles of generation are found in separate organisms, and the first phase in the argument rests fundamentally on what may be called the Axiological Axiom: Being is better than non-being. We will divide this passage into two parts and discuss each part in order. Here is the first part of the passage in question (GA 2.1, 731b22-31):

\footnotetext{
${ }^{55}$ Others have expressed the sentiment that reproduction is fundamentally about the individual organism rather than the species. Rodier insists that 'il n'est pas question ici de l'espèce, mais de l'individu', but does not explain why (1907, 230, emphasis original); Ross says that both nutrition and reproduction are 'forms of self-preservation', but does not explain how $(1961,228)$. Balme claims that the preservation of the species 'follows from the individual's attempt to preserve its own form' (1987a, 280), but elsewhere explains that the preservation of the species is how this is accomplished as a 'second-best' to nutritive self-maintenance (1992, 96-7). Rashed similarly argues for the importance of the concept of self-preservation in Aristotle's biology, but ultimately asserts the preservation of the species as a higher end (2002, 54-9). Johnson specifically rejects the idea that the species itself could be the ultimate beneficiary of reproduction, but then simply insists that perpetuating the species must somehow be beneficial to the individual organism $(2005,175-8)$. Leunissen similarly rejects species preservationism, but contrasts reproduction with nutrition's self-preservative goal and so fails to explain how reproduction could achieve anything for the organism's 'own individual good' (2012, 63-4). Gotthelf's take is better: 'it is crucial to remember that reproduction is, for Aristotle, an extension of self-preservation: the animal is unable to preserve itself eternally, so it does the next best thing towards its preservation - it leaves behind something essentially like itself. The aim is self-preservation, not preservation of the species. (The latter is a consequence of the former)' (2012b, 58, emphasis original; cf. 2012a, 8-9 n. 13). Among available interpretations, Polansky captures the truth of the matter best: 'Most natural to mortal things is to seek godlike life for themselves so far as they are able. Aristotle does not say that the individual aims to perpetuate the species, or anything so removed from his topic as that, but rather that the living thing produces another such as itself ... In this way it preserves its own life as much as it can ... [T] he generation of offspring is the making of another self capable of continuing its very own life and so the extending of nutritive life' (2007, 205, emphasis original). None of these commentators attempt to explain how, exactly, reproduction serves to preserve an individual organism's own being, life, or self. By contrast, Katayama and Quarantotto (discussed below) both argue that Aristotle's theory of embryogenesis shows how individuals can preserve themselves through reproduction (Katayama 1999, 91-8; Quarantotto 2005, 329-31, 336-7). More recently, Cerami has endorsed Gotthelf's position and argued that self-preservation can serve as a criterion for Aristotle's hierarchical 'scale of being' (2018, 141-9).

${ }^{56}$ Sometimes $G A 4.3,767 \mathrm{~b} 9-10$, where he says that sexual difference is a necessary condition for 'preserving the

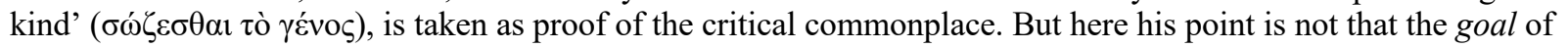
reproduction is species preservation, but rather simply that reproduction (and hence the continuity of the kind) does in fact require both male and female organisms. Cf. Henry 2007, 262.
} 


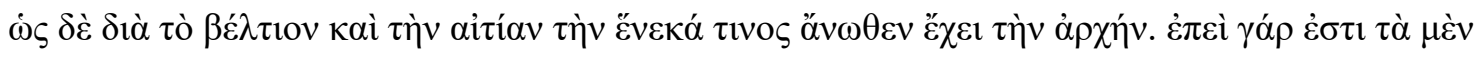

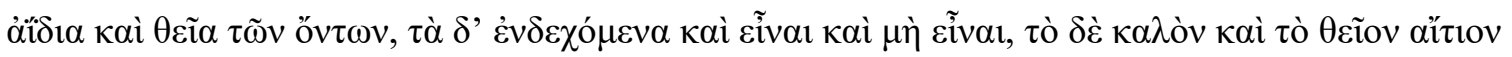

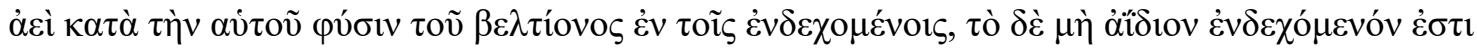

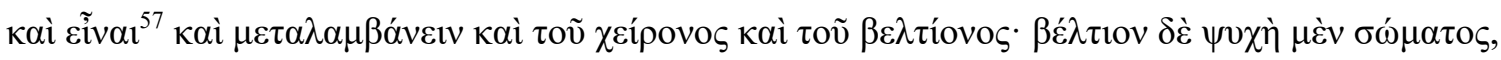

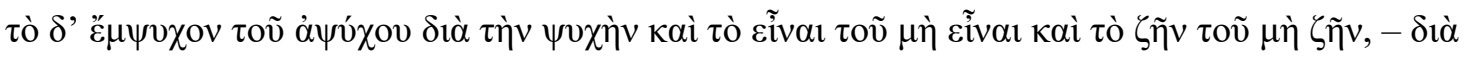

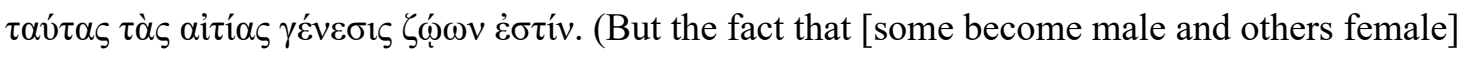
for the better and on account of the cause for the sake of something involves a higher principle. For since some beings are eternal and divine, while others are able both to be and not be, and the beautiful and divine is always, in virtue of its own nature, a cause of the better in those that are able, while that which is not eternal is able to be and to partake of the worse and the better, and since soul is better than body, and what is ensouled is better than what is without soul on account of the soul, and being is better than non-being and living than not living - on account of these causes there is a generation of animals. $)^{58}$

Up to this point in the text, the argument from a 'higher principle' appears to be:

1. Of things that are, some are eternal, while some can either be or not-be (731b24-5).

2. The beautiful/divine is naturally a cause of the better in that which is capable (of being better? of being and not-being?) (731b26-7).

3. Perishable things are also capable of being, and participating in both the worse and the better, (i.e. they are not always becoming, as Diotima claims) (731b27-8).

But how can they participate in the better? Well ...

4. Soul is better than body, and the ensouled is better than the soulless on account of soul (731b28-9).

- [Reminder: Perishable beings, though perishable, are capable of being.]

5. Being is better than non-being, and [i.e.?] living than non-living (731b30-1).

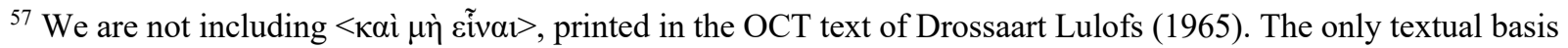
for this addition, according to the apparatus criticus, is the Arabic translation of al-Bitriq; it is also recommended by Platt 1912 without justification, and Peck 1942 has both the Greek and its translation in angle brackets. Balme 1992, 155 comments: 'Platt's addition " $<$ and not being>" is probably wrong, because the argument has moved on: in calling these things "non-eternal" Aristotle grants that they must perish, but he now says that in spite of being noneternal they are nevertheless capable of being.'

${ }^{58}$ In parsing the structure of this difficult passage we follow Balme 1992. For alternative takes see Platt 1912 and Peck 1942. 
- [Another reminder: soul is the source and cause of being and life (DA 2.4, 415b12-14).]

6. And on account of these causes there is a generation of animals (731b31).

At this point the reader will be aware of a significant lacuna in the argument! Fortunately, the second part of the passage is intended to fill that lacuna, but it depends implicitly on the previously stated Axiological Axiom (GA 2.1, 731b31-732a1):

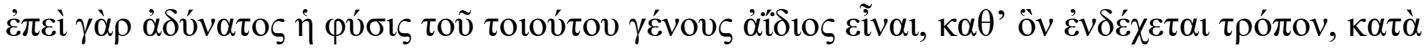

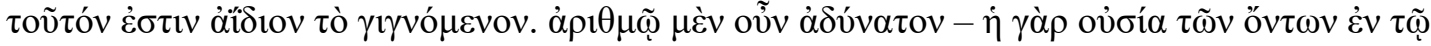

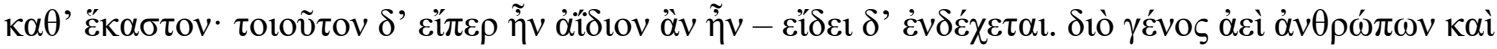

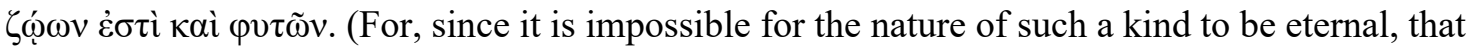
which comes into being is eternal in the way in which it is capable. Now it is not possible [for that which comes into being to be eternal] in number (for the being of existing things is in the particular, and if [the particular] were such it would be eternal [in number]); but [that which comes into being] is capable [of being eternal] in form. Wherefore there is always a kind - of human beings, animals and plants.)

Aristotle here denies that reproduction is an act of becoming one with the eternal species. There is no eternal species, unless as a consequence of reproducing individuals. ${ }^{59}$ Two features about the way this passage is worded point to this conclusion. First, the goal of reproduction is for the perishable individual to be eternal in the only way possible for it; the continued existence of these 'kinds' is a consequence of reproduction, not what it is for. And Aristotle again emphasizes that it is the particular organism, $\gamma(\gamma v o ́ \mu \varepsilon v o v$, which is capable of being eternal through reproduction. Second, note the plurals: there is always a kind, of human beings, of animals and of plants. In an earlier paper, Lennox noted that the context here indicates that $\gamma \varepsilon \dot{\varepsilon}$ os (kind) be understood in its etymologically primitive sense, given as its first meaning in Metaphysics $\Delta .28$ : 'a continuous generation of things having the same form; for example,

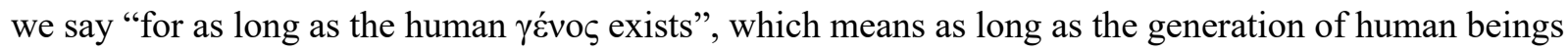
continues' (1024a29-31). ${ }^{60}$ When Aristotle concludes that reproduction ensures that there is always a

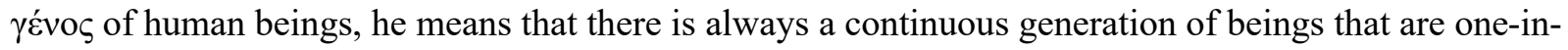
form.

${ }^{59}$ On this point, see Balme 1987a, 280; Gotthelf 2012b, 58 and 2012c, 71 n. 14.

${ }^{60}$ Cf. Lennox 1985 70-1 (=2001b, 135). This reading has been given further support in Henry 2008. 
Let us now return to the question with which we began: why does Aristotle hold that reproduction and nutrition are two functions of one power or capacity of the soul, the nutritive capacity? Recall one of our key passages on this topic (DA 2.4, 416b9-19):

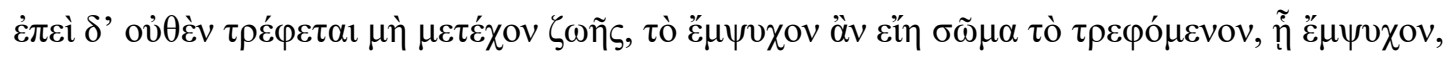

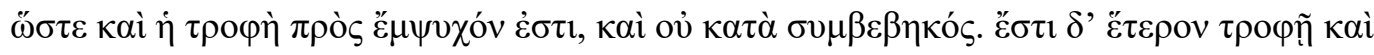

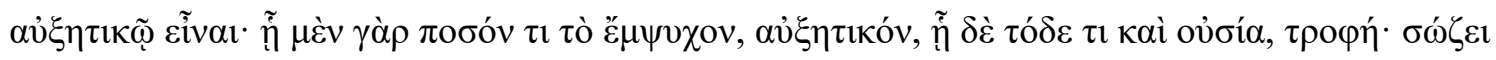

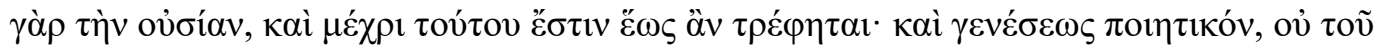

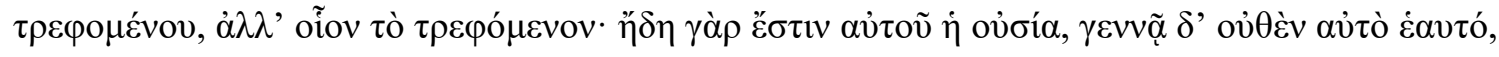

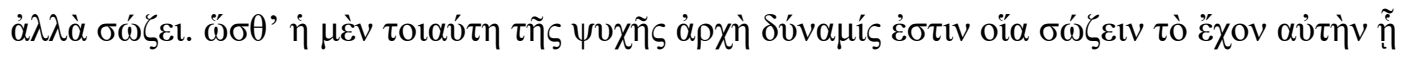

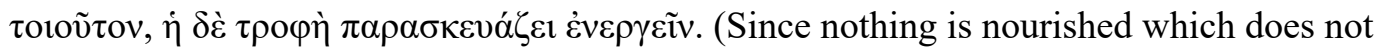
participate in life, that which is nourished would be the ensouled body insofar as it is ensouled; and so nutrition is relative to the ensouled, and not in an incidental way. Being nutrition is different from being growth-promoting. For insofar as the ensouled thing is a certain quantity, [this capacity] is growth-promoting, but insofar as the ensouled thing is a this and a substantial being, [this capacity] is nutrition. For [this capacity] preserves the substantial being, and [the substantial being] is for just so long as it is nourished. And [this capacity] is productive of generation, not of the thing nourished, but of one like the thing nourished; for the substantial being of this [i.e. of the thing nourished] already is, and nothing itself begets itself, but it does preserve itself. Hence this sort of principle of the soul is a capacity such as to preserve the thing having this capacity as such, and the nutrients furnish the activity [of the capacity].

First, Aristotle identifies the object of the nutritive power, the focus to which its activity is directed and related: that which is nourished, the ensouled body qua ensouled. Then he goes on to characterize the relation between capacity and object. The capacity preserves its object, and generates another like its object. But he cautions the reader: do not therefore identify nutritive self-maintenance as a form of selfgeneration, a process of continually becoming oneself (and he is perhaps thinking here of Diotima's

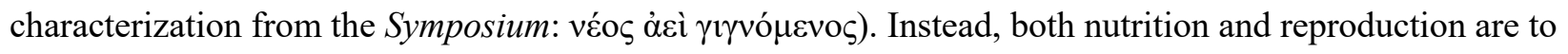
be conceived as forms of self-maintenance, as ways in which the organism preserves its own being. This is why, after identifying the object and characterizing the capacity's relation to it, he says the result of his analysis $(\check{\sigma} \sigma \theta \varepsilon, 416 \mathrm{~b} 17)$ is that this principle of the soul (again, referring back ultimately to $\dot{\eta} \alpha \hat{\tau} \tau \dot{\eta}$ $\delta v ́ v \alpha \mu \iota \tau \tilde{\eta} \varsigma$ $\psi v \chi \tilde{\eta} \varsigma$ from 416a19) is fundamentally preservative of the living being 'as the sort of thing it

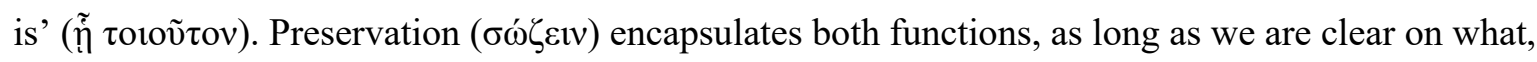
exactly, is being preserved. The nutritive capacity preserves the organism as the sort of thing it is: qua 
enformed, or qua ensouled. As we have seen, nourishing the ensouled body does not mean maintaining the matter (which is constantly being replenished), but rather maintaining the form in the matter, the functional capacity of the body's parts. Reproducing the ensouled body accomplishes the same thing, for what is generated is another one 'like the thing nourished', one in form with the ensouled body of the parent. So reproduction likewise instills the same form in other matter (Metaph. Z.8, 1034a2-5). In this way, the reproductive capacity also has the ensouled body qua ensouled as its object. Hence, when discussing the nutritive principle found in the heart, he claims that 'that which is productive and reproductive, as such, is relative to ( $\left.\pi \rho \rho_{\varsigma}\right)$ that which is produced and reproduced' (GA 2.6, 742a30-1). Nourishment and reproduction have one and the same object: the ensouled body qua ensouled. Nourishing the ensouled body and reproducing the ensouled body accomplishes one and the same goal: the preservation of the organism's form. Two functions, yet one object and goal. Hence, one capacity: the nutritive soul.

But what does it really mean that reproduction maintains the form of the parent? And how exactly does reproduction serve to maintain the parents themselves? Just as with the theory of nutrition, we want the detailed biological analysis that shows how the overarching ontological picture is actually supposed to work. To this end, and to address the second problem with which we began (why not 'reproductive soul'?), we now turn to an important passage from GA 2.4. Here Aristotle draws together many threads from earlier in $G A$ into a single argument meant to show the identity of the nutritive and reproductive capacities (GA 2.4, 740b24-741a3):

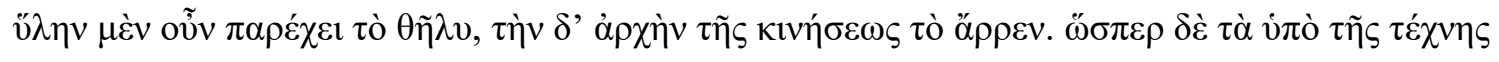

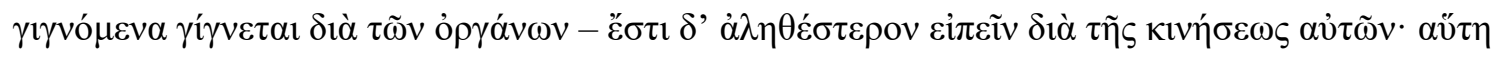

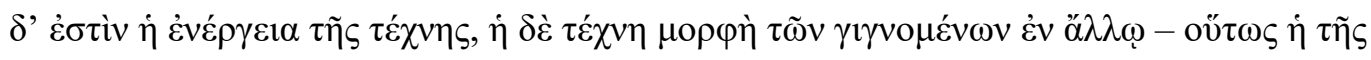

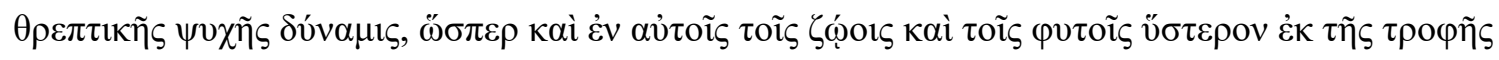

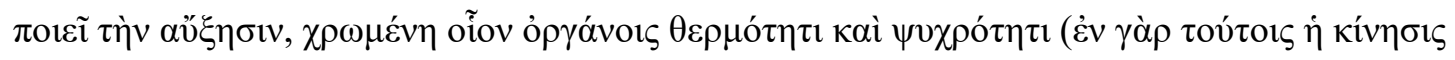

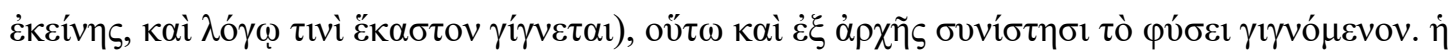

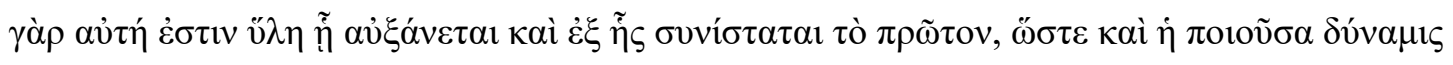

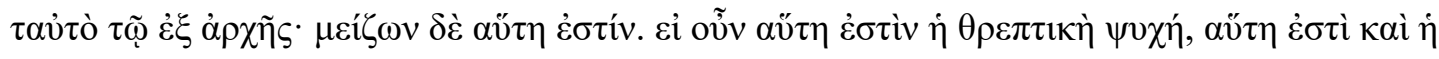

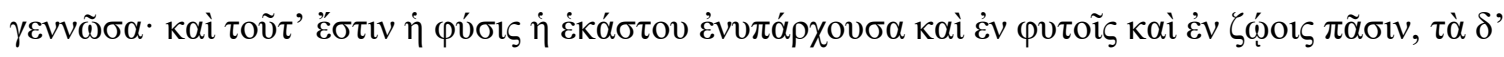

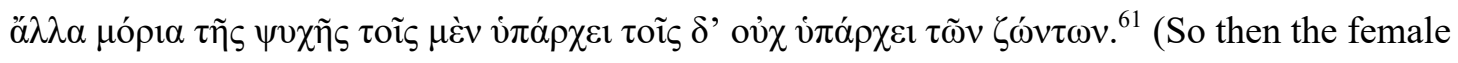
provides the matter, while the male provides the source of motion. Just as the things which cometo-be by art come-to-be through tools - yet it is more true to say that they come-to-be through the

${ }^{61}$ The Greek text is from Drossaart Lulofs 1965; we alter his punctuation slightly in our translation. 
motion of these tools - and this motion is the activity of the art, while the art is the shape of the things which come-to-be, present in another [i.e. in the mind of the artisan], so too the capacity of nutritive soul [is the shape of the things which come-to-be, present in another]; just as later it [i.e. the capacity of nutritive soul] produces growth in these animals and plants from the nourishment, using heat and cold like tools (for that motion is present in these [i.e. heat and cold], and each thing comes-to-be according to a certain $\log o s$ ), so too in this manner the thing coming-to-be by nature is constituted from the beginning. For the matter by means of which it grows and from which the first thing is constituted are the same, so that also the producing capacity is the same as [the capacity] from the beginning. ${ }^{62}$ But this [i.e. the latter, the capacity from the beginning] is greater. If then this is the nutritive soul, this is also the reproductive soul. And this is the nature of each thing, present in all plants and animals, while the other parts of soul are present in some living things, but not present in others.)

Here Aristotle summarizes his established analogy between the male's contribution to reproduction and the artisan's activity of production. Just as the form of the product in the minds of artisans (i.e. their knowledge) 'moves' their hands, which in turn move their tools, which in turn shape the material, so (in animals that emit semen) the semen 'possesses movement in actuality' (GA 1.22, 730b21; cf. 2.1, 734b8, 22-3) derived from the male parent and is used as a 'tool' to shape the katamenia (GA 1.22, 730b8-23). ${ }^{63}$ The motion of the artisan's tools contains the logos of the art (and thus the form of the product) by virtue of enacting a precisely-ordered sequence of steps necessary for creating and assembling various parts into a functional whole. Similarly, the movement of the semen derived from the male parent contains 'the logos by virtue of which this is now flesh, and that bone', i.e. the ordered procedure according to which the various instrumental parts of the body are to be constructed from those uniform parts and organized into an animal (GA 2.1, 734b28-735a2). Because the uniform parts are formed from the katamenia by means of heating and cooling, this ordered procedure indicates the sequence, location, intensity etc. of the heating and cooling needed to generate those parts in exactly this pattern. ${ }^{64}$ It ensures that what is generated at each stage of development is not just an indeterminate mass of flesh or bone, but a well-

${ }^{62}$ The neuter $\tau \alpha \dot{\tau} \tau$ ó produces $\tau \tilde{\varphi} \dot{\varepsilon} \xi \dot{\alpha} \rho \chi \tilde{\eta} \varsigma$ at b36 (where we would expect $\tau \tilde{\eta} \tilde{\varepsilon} \xi \dot{\alpha} \rho \chi \tilde{\eta} \varsigma$ ), referring to the nutritive capacity of the father. We have been helped in dealing with this puzzling sentence by correspondence with Jessica Gelber and David Lefebvre.

${ }^{63}$ On the nature of the movement present in semen, cf. Connell 2016, Ch. 5; de Ribera-Martin 2019; Quarantotto forthcoming.

${ }^{64}$ We are here putting aside a variety of exegetical problems about the capacity transmitted by the male semen and its relationship to the instrumental heating and cooling, as well as to the special heat of the pneuma, used by that productive or generative capacity. 
shaped, correctly positioned and properly interconnected structure of uniform parts. Thus, the instrumental parts are generated simultaneously with the uniform parts that constitute them (GA 2.1, 734b27-8). As we have seen, Aristotle argues that nutritive self-maintenance works in a similar way: the instrumental parts of the body are maintained simultaneously with their uniform parts. Quarantotto has shown how Aristotle's understanding of the father's role as a principle of motion unites the two analyses. ${ }^{65}$ The motion which belongs to the semen, and is imparted to the katamenia, is the very same nutritive motion by which the father assimilates blood to his own bodily parts $(G A 2.3,737 \mathrm{a} 18-22){ }^{66}$ As Quarantotto and others argue, this explains how nutrition and reproduction comprise a single, unitary process for Aristotle. ${ }^{67}$ With respect to our GA 2.4 passage above, it also explains why Aristotle claims that the source of motion in reproduction is the nutritive capacity of the father. ${ }^{68}$ In technical production, the form of the product directs the motion of the artisan's hands and tools in the precise way necessary to replicate the structure already present in the artisan's mind. In natural reproduction, the nutritive capacity imbues the semen with the same ordered procedure by means of which this capacity maintains the parts of the father's own body. The process by which the parts are generated in the katamenia is exactly the same as the process by which identical parts are maintained in the father's own body, and as will 'later' continue to be developed and maintained in the offspring's body: the semen carries the exact same nutritive motion, determined by the same logos, using heat and cold in precisely the same way to create the same kind of parts out of the same kind of material. ${ }^{69}$ Hence, the capacity by which the male nourishes itself is the same as the capacity by which it reproduces itself.

Quarantotto further contends that the continuity of the motion transmitted by the semen entails the continuity of the same nutritive, living activity between father and offspring. ${ }^{70}$ Katayama has likewise shown how Aristotle's theory of embryogenesis stipulates a unity of the nutritive power between parent and offspring, such that to be 'one in form' means to share that single capacity across generations. ${ }^{71}$ Indeed, Katayama points out that Aristotle draws this remarkable conclusion in the GA 2.4 passage

\footnotetext{
${ }^{65}$ Quarantotto 2005, 329-31, 336-7, and forthcoming.

${ }^{66}$ On this claim, cf. also Moraux 1955, 293; Balme 1987b, 292-3 and n. 14; Cooper 1990, 57-9, 63; Gotthelf 2012d, 97-8; Johansen 2012, 140 and n. 36; Cerami 2015 137, 149; Cerami 2018, 138; Pellegrin 2018; Gelber forthcoming; Lefebvre forthcoming.

${ }^{67}$ Quarantotto forthcoming; cf. also Pellegrin 2018 and Gelber 2020 and forthcoming.

${ }^{68}$ Cf. GA 2.1, 735a15-19: 'It is necessary for that part to come to be first which possesses the source of growth; for this, the nutritive capacity, is present alike in all living things whether plant or animal. But this is the capacity to reproduce another like itself; for this is by nature a function of every perfect animal and plant.'

${ }^{69}$ As we have seen in $P A$, blood functions as the matter for the parts of the body by being potentially any and all such parts. The 'blood-like' katamēnia, which is formed from an excess of blood in the uterus, shares the same essential character ( $G A 2.3,737 \mathrm{a} 22-5)$.

${ }^{70}$ Quarantotto 2005 336-7 and forthcoming. Cf. also Preus 1975, 93-5; Katayama 1999, 91-8; Lefebvre forthcoming.

${ }^{71}$ Katayama 1999, Ch. 6. Henry, by contrast, insists that there are two distinct powers at play (cf. Henry 2019 , Ch. 7).
} 
above. $^{72}$ In the process of generation, the nutritive capacity of the father and the nutritive capacity of the incipient organism are one and the same: 'the producing capacity [by means of which the embryo grows] is the same as [the capacity] from the beginning.' Aristotle invites us to consider the dual role that the katamenia plays in reproduction: the matter from which the heart is first constituted and the matter by means of which the embryo starts to develop its own parts are the same (cf. GA 2.4, 740b2-8 just previous, where he says that some of the katamenia becomes blood within the embryo's new heart, serving as initial nourishment for its development before the umbilical cord appears). Just as the material from which it is generated and by means of which it initially develops are the same, so too the source of motion for its generation and for its development are the same. In other words, the generative power of the father is the same as the nutritive power of the incipient embryo. Hence Aristotle says that, when we consider the motion of the male as a way of generating the form-in-the-matter, it makes no difference whether we speak of the motion of the semen, the motion which sets the katamenia from the beginning, or the motion which makes each of the parts grow, 'for the logos of the motion is the same' (GA 4.3, 767b15-20).

The father's nutritive capacity originates a source of motion in the offspring that carries out and perpetuates the very nutritive activity that originated it. ${ }^{73}$ In this sense, the nutritive capacity of the developing embryo and the nutritive capacity of the father are one and the same. The continuity of nutritive activity between parent and offspring can then be further perpetuated once the offspring matures and generates offspring of its own, and this cycle can continue in a potentially infinite line of succession. While the parents themselves cannot exist eternally, their nutritive powers can persist indefinitely. Indeed, as Katayama notes, this idea is an important premise in Aristotle's theory of heredity in $G A 4.3 .^{74}$ The similarity of offspring to father, mother, or to more distant ancestors on either side are to be explained by the complex interplay of nutritive 'motions' that are carried on (either actually or only as a potentiality) by the offspring from their progenitors. Hence Aristotle describes how, if conditions are right, the nutritive motions of the father present in his offspring can give way to those of the grandfather, or to those of the great-grandfather, or to ancestors even further back (and, similarly, to those of the mother and her

\footnotetext{
${ }^{72}$ Katayama 1999, 92-3.

${ }^{73}$ This highlights the essential difference between artistic production and natural generation: while 'the art is the source and form of the thing coming-into-being, but in another, the motion of nature is in [the thing coming-to-be] itself, from another natural being that has the form in actuality' (GA 2.1,735a2-4). Artistic production entails an external source of motion; the development of a living thing entails an internal source of motion that originates externally. In natural generation, it is as if the artisan's capacity to build could be present in the wood itself rather than within the artisan (Phys. 2.8, 199b28-9).

${ }^{74}$ Katayama 1999, 96.
} 
ancestors) (cf. GA 4.3, esp. 768a11-21). In each instance, these nutritive motions of long-dead ancestors are indeed present (either actually or as a potentiality) in each successive generation. ${ }^{75}$

In light of our previous analysis, we can draw several conclusions from the GA 2.4 passage.

(1) The passage supports our solution to Problem 1 (One or two antikeimena?) by tying the physiological account of formal self-maintenance from $P A$ 2-3 to the account of reproduction. Ultimately, Aristotle proposes a single, coherent narrative of how the activity of one capacity can both transform blood to maintain the parts of the body (and thus its own functional identity), and act on the blood-like katamenia to generate the parts of the embryo (and thus its functional identity). In both instances, the same capacity originates the same motion within the same kind of material, using the same 'tools' in the same way. The single antikeimenon of both activities is the ensouled body, qua ensouled, for this is what is nourished and what is reproduced.

(2) The passage also provides an answer to Problem 2 (Why not 'reproductive soul'?) While Aristotle claims in $D A 2.4$ that it would be 'just' to call the primary kind of soul 'reproductive' soul (416b23-5), ultimately he (rightly) prefers to call it 'nutritive soul' on account of the fact that reproduction is accomplished by means of imbuing the katamenia with the very same nutritive activity that assimilates blood to the father's bodily parts. ${ }^{76}$ Reproduction is properly an activity of the nutritive capacity. This is also why he insists that the originating capacity 'from the beginning' is 'greater' ( $\left.\mu \varepsilon^{\prime} \zeta \omega v\right)$ : while the embryo's incipient heart does contain the source of its own development, this source carries out and perpetuates the nutritive activity initiated by the father via the semen.

(3) By the same token, the passage helps us understand why Aristotle believes that reproduction allows the individual parent to be eternal, in a way. In the development of the embryo, the nutritive capacity of the father and of the offspring are, in a sense, identical. Yet the activity of this nutritive capacity persists as the offspring's own self-maintenance even after this developmental process has concluded. As Katayama and Quarantotto have argued, this continuity of activity between parent and offspring articulated in the $G A$ helps explain how individual plants and animals can 'participate in the eternal and the divine' (DA 2.4, 415a26-b1). ${ }^{77}$ Reproduction can be understood as a form of selfpreservation; not, of course, as a way of persisting one in number, but nevertheless as a way in which the very activity that constitutes the functional identity, and thus the being, of the parent can continue beyond its own finite life-span. This also helps explain why Aristotle sometimes insists on the ultimate priority of the reproductive function, or even claims it is the only function of some organisms. Because all mortal life

\footnotetext{
${ }^{75}$ For further discussion of Aristotle's theory of heredity and how the nutritive 'motions' of the mother and her ancestors enter into that theory, cf. Cooper 1990, 64-73; Gelber 2010; Connell 2016, Ch. 9.

76 Substantively the same solution to the problem is proposed by Pellegrin 2018, 85 .

${ }^{77}$ Cf. Katayama 1999, Ch. 6 (esp. pp. 91-8); Quarantotto 2005, 336-7.
} 
must eventually end, reproduction is the culmination and completion of all of an organism's selfpreservative efforts.

\section{Conclusion}

This final point is the most difficult aspect of Aristotle's metaphysics of reproduction, but is also the most vital for his teleological explanation of it. Why is the mother octopus with which we began compelled to starve herself? The common refrain in the literature that reproduction is for the sake of 'preserving the species' is untenable. How then can Aristotle explain the octopus' behavior? Correctly understanding the teleology of reproduction, we argue, requires us to appreciate instead how an organism's own being is implicated in the act of leaving behind another such as itself. If the octopus' own persistence were not somehow at stake in the act of successful reproduction, then the goals of nutrition and of reproduction would be fundamentally at odds with one another, as is clear in any case where successful reproduction is fatal for one or both of the generating organisms. If, on the other hand, the octopus itself does persist in some way through its offspring, then Aristotle has a very neat explanation for why nutrition and reproduction are ultimately one and the same biological function: both achieve formal self-maintenance for the individual. This goal is achieved by a single power to generate and maintain complex functional structures of uniform parts. As Quarantotto et al. have argued, nutritive soul is the principle of a single activity or process. Acting on an organism's own blood, this power is nutritive self-maintenance; acting on the katamenia, it is reproductive self-maintenance. This understanding of the teleological and biomechanical unity of the two functions thus confirms and supports our argument regarding the single antikeimenon of the nutritive soul. Nutrition and reproduction comprise a unitary activity, which engages with one and the same object (the ensouled body, qua ensouled) by maintaining and preserving it.

But how could this be, when Aristotle also clearly insists that the organism does not persist as 'itself', but only as something 'like itself' (DA 2.4, 415b6-7)? Isn't it only a likeness of oneself that is left behind in reproduction, i.e. another creature that is of the same species as oneself? On the contrary, we have shown that the oneness in form between the parent and offspring is a much stronger ontological relationship than mere similarity or sharing of 'species form'. An interesting discussion of familial affection in $N E 8$ indicates how Aristotle envisages this stronger form of identity ( $N E 8.12,1161 \mathrm{~b} 27-33)$ :

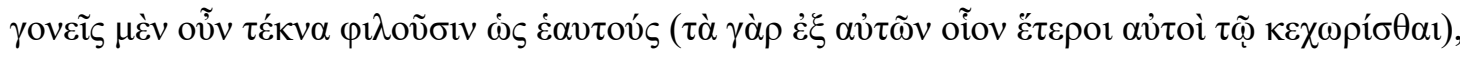

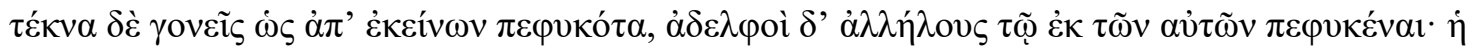

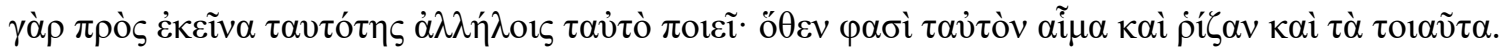

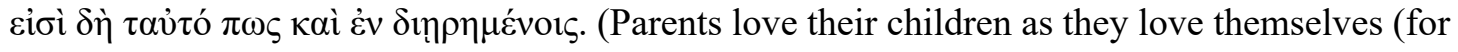
those things that come from them are like other selves by virtue of their being separated), while 
children love their parents as being born from them, and brothers love each other by virtue of being born from the same parents, for their sameness with their parents makes them the same as each other. This is why they speak of 'the same blood' or 'root' or some such. They [i.e. parent and child] are indeed somehow the same, even in their having been divided.)

The love, care, and attention which parents are naturally disposed to give their children is cast here as a reflection of our own natural disposition to love and care for ourselves: children are 'other selves' for parents. $^{78}$ Caring for children is thus a form of self-care. Although the context here in $N E 8$ is clearly a human one, it is not difficult to see how such analysis could be extended to the animal kingdom at large. ${ }^{79}$ Indeed, the behavior of our mother octopus is best explained in those terms. The GA 2.4 passage we have discussed can be seen as providing an explanation for how exactly offspring are 'other selves' for their parents and for how parents (and in particular, the father) are 'somehow the same' as their offspring. ${ }^{80}$ As Katayama and Quarantotto assert, there is one power at work throughout the activity of reproduction, embryogenesis, and the development of a new organism. Insofar as the fetus continues the nutritive activity which originated it, the father's generative capacity does not differ from the fetus' growthpromoting capacity. And because of the continuity of nutritive activity from generation until death, there is simply no temporal point at which we can say that now the power which belongs to the offspring is different from the power of the father. The father and the offspring are different organisms, and yet the capacity which maintains each is nevertheless identical. The father is the 'same' as the offspring, then, just insofar as they share this one nutritive power. In other words, while the father and offspring are not one in number, they are in fact one in form.

The conception of form at work in Aristotle's understanding of biological nutrition and reproduction is thus not one of 'species form' at all. Instead, Aristotle is concerned to identify the powers belonging to particular organisms by which they perpetuate their own existence. The nutritive power in question is what is responsible for the generation and maintenance of the functional identity for both the father and his offspring. Because this power is shared between them, the persistence of the offspring

${ }^{78}$ Compare NE 9.7, 1167b33-1168a9. Artisans love their works; poets most of all, who love their poems 'like children'. 'The cause of this is that being is desireable and loveable for all, and we are by virtue of activity (for we are by living and acting), while the work is, in a way, the producer in activity. So he loves the work, because he loves being. And this is natural, for that which is in potential, the work reveals in activity'. Shortly thereafter, in an interesting inversion of the father-focused $G A$ analysis, Aristotle emphasizes that this explains why mothers are 'more loving of children' (than fathers?): 'For giving birth is more laborious [than the father's contribution?], and [mothers] know moreso that [children] are of themselves' (NE 9.7, 1168a24-6).

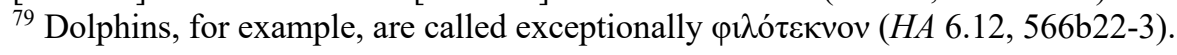

${ }^{80}$ Aristotle's theory of heredity (discussed above) shows how this can be true for the mother and for female ancestors generally, albeit not to the same degree of perfection. 
ensures that something essential of the father's own being - the power which grounds, gives rise to and preserves his identity - can persist even beyond his mortal lifespan. While individual organisms cannot persist eternally, such powers can endure through the generations, handed down from parent to offspring in a potentially infinite line of succession. This explains why reproduction achieves something good for the individual parent, even if successfully doing so involves great hardship and even death. The existence of the offspring guarantees that the parent themselves can persist in the way possible for mortal things: for their own nutritive power to endure in their offspring. The 'preservation of the species' does not enter the equation here; rather, the continuation of natural kinds is simply the result of individual organisms achieving the final cause of preserving their own being. No mortal living thing can be eternal, but through reproduction a facet of itself endures. In this way, mortal life participates in the eternal and the divine. ${ }^{81}$

\section{Bibliography}

Apostle, H. G., trans. (1981). Aristotle's on the Soul (De Anima). Grinnell.

Balme, D. M. (1987a). Teleology and Necessity. In: A. Gotthelf and J. G. Lennox, eds., Philosophical Issues in Aristotle's Biology. Cambridge, pp. 275-85.

Balme, D. M. (1987b). Aristotle's biology was not essentialist. In: A. Gotthelf and J. G. Lennox, eds., Philosophical Issues in Aristotle’s Biology. Cambridge, pp. 291-312.

Balme, D. M., trans. (1992). Aristotle: De Partibus Animalium I and De Generatione Animalium I (with Passages from II.1-3). Oxford.

Balme, D. M., ed. (2002). Aristotle: Historia Animalium Volume I, Books I-X: Text. Cambridge.

Bodéüs, R., trans. (1993). Aristote: De L'âme. Paris.

Cerami, C. (2015). Génération et Substance: Aristote et Averroès entre physique et métaphysique. Berlin.

Cerami, C. (2018). Function and Instrument: Towards a New Criterion of the Scale of Being in Aristotle's Generation of Animals. In: A. Falcon and D. Lefebvre, eds., Aristotle's Generation of Animals: A Critical Guide. Cambridge, pp. 130-149.

\footnotetext{
${ }^{81}$ We would like to thank Victor Caston for pushing us to clarify an important aspect of our argument, as well as an anonymous referee for their valuable comments. In addition, we thank Jessica Gelber and David Lefebvre for several helpful exchanges. Coates would also like to thank Julie Ward for a stimulating seminar on the $D A$ in spring 2014, where several ideas presented here had their early formulation in a term paper.
} 
Code, A. (2004). On Generation and Corruption I.5. In: F. De Haas and J. Mansfeld, eds., Aristotle: On Generation and Corruption, Book I, Symposium Aristotelicum. Oxford, pp. 171-93.

Connell, S. M. (2016). Aristotle on Female Animals: A Study of the Generation of Animals. Cambridge.

Cooper, J. M. (1990). Metaphysics in Aristotle's Embryology. In: D. Devereux and P. Pellegrin, eds., Biologie, logique et métaphysique chez Aristote. Paris, pp. 55-84.

Corkum, P. (2016). Ontological Dependence and Grounding in Aristotle. In: Oxford Handbooks Online. $\mathrm{URL}=$ https://www.oxfordhandbooks.com/view/10.1093/oxfordhb/9780199935314.001.0001/oxfordhb9780199935314-e-31

Diamond, E. (2015). Mortal Imitations of Divine Life: The Nature of the Soul in Aristotle's De Anima. Evanston.

Drossaart Lulofs, H. J., ed. (1965). Aristotelis: De Generatione Animalium. Oxford. Duncombe, M. (2015). Aristotle's Two Accounts of Relatives in Categories 7. Phronesis 60, pp. 436-61. Everson, S. (1995). Psychology. In: J. Barnes, ed., The Cambridge Companion to Aristotle. Cambridge, pp. 16894.

Foster, K., and Humphries, S., trans. (1951). St. Thomas Aquinas: Commentary on Aristotle's De Anima. Notre Dame.

Freudenthal, G. (1995). Aristotle's Theory of Material Substance: Heat and Pneuma, Form and Soul. Oxford.

Furth, M. (1988). Substance, Form, and Psyche: An Aristotelean Metaphysics. Cambridge.

Gelber, J. (2020). Soul's Tools. In: H. Bartoš and C. G. King, eds., Heat, Pneuma, and Soul in Ancient Philosophy and Science. Cambridge.

Gelber, J. (forthcoming). Aristotle on Seed. In: C. Cohoe, ed., Aristotle's De Anima: A Critical Guide. Cambridge.

Gill, M. L. (forthcoming). Method and Nutritive Soul in Aristotle's De Anima II.4. In: R. Lo Presti and G. Korobili, eds., Nutrition and Nutritive Soul in Aristotle and Aristotelianism. Berlin.

Gotthelf, A. (2012a). Aristotle's Conception of Final Causality. In: Teleology, First Principles and Scientific Method in Aristotle's Biology. Oxford, pp. 3-44.

Gotthelf, A. (2012b). The Place of the Good in Aristotle's Natural Teleology. In: Teleology, First Principles and Scientific Method in Aristotle's Biology. Oxford, pp. 45-66. 
Gotthelf, A. (2012c). Understanding Aristotle's Teleology. In: Teleology, First Principles and Scientific Method in Aristotle's Biology. Oxford, pp. 67-89.

Gotthelf, A. (2012d). Teleology and Embryogenesis in Aristotle's Generation of Animals II.6. In:

Teleology, First Principles and Scientific Method in Aristotle's Biology. Oxford, pp. 90-116.

Hamlyn, D. W., trans. (1993). Aristotle: De Anima Books II and III (with Passages from Book I). Oxford.

Harari, O. C. (2011). The Unity of Aristotle's Category of Relatives. The Classical Quarterly 61, pp. 521-37.

Henry, D. (2007). How Sexist is Aristotle's Developmental Biology? Phronesis 52, pp. 251-69.

Henry, D. (2008). Organismal Natures. Apeiron 41, pp. 47-74.

Henry, D. (2015). Aristotle on the Cosmological Significance of Biological Generation. In: D. Ebrey, ed., Theory and Practice in Aristotle's Natural Science. Cambridge, pp. 100-18.

Henry, D. (2019). Aristotle on Matter, Form, and Moving Causes: The Hylomorphic Theory of Substantial Generation. Cambridge.

Hicks, R.D., ed. and trans. (1907). Aristotle: De Anima. Cambridge.

Johansen, T. K. (2009). From Plato's Timaeus to Aristotle's De Caelo: The Case of the Missing World Soul. In:

A. C. Bowden and C. Wildberg, eds., New Perspectives on Aristotle's De Caelo. Leiden, pp. 9-28.

Johansen, T. K. (2012). The Powers of Aristotle's Soul. Oxford.

Johnson, M. R. (2005). Aristotle on Teleology. Oxford.

Kirwan, C., trans. (1993). Aristotle: Metaphysics Books $\Gamma$, A, and E. Oxford.

Katayama, E. G. (1999). Aristotle on Artifacts: A Metaphysical Puzzle. Albany.

Kupreeva, I. (2005). Aristotle on Growth: A Study of the Argument of On Generation and Corruption I 5. Apeiron 38, pp. 103-59.

Lennox, J. G. (1985). Are Aristotelian Species Eternal? In: Gotthelf, A., ed., Aristotle on Nature and Living Things. Pittsburgh, pp. 67-94. [Reprinted in Lennox 2001b, pp. 131-159.]

Lennox, J. G., trans. (2001a). On the Parts of Animals. Oxford.

Lennox, J. G. (2001b). Aristotle's Philosophy of Biology: Studies in the Origins of Life Science. Cambridge. Lennox, J. G. (2010a). Bíos, $\pi \rho \tilde{\alpha} \xi 1 \varsigma$ and the Unity of Life. In: S. Föllinger, ed., Was ist 'Leben'? Aristoteles' Anschauungen zur Entstehung und Funktionsweise von Leben. Stuttgart, pp. 239-59. 
Lennox, J. G. (2010b). Bios and Explanatory Unity in Aristotle's Biology. In: D. Charles, ed., Definition in Greek Philosophy. Oxford, pp. 329-55.

Lennox, J. G. (forthcoming). 'Most Natural Among the Functions of Living Things' Puzzles about Reproduction as a Nutritive Function. In: R. Lo Presti and G. Korobili, eds., Nutrition and Nutritive Soul in Aristotle and Aristotelianism. Berlin.

Lefebvre, D. (forthcoming). Looking for the Formative Power in Aristotle's Nutritive Soul. In: R. Lo Presti and G. Korobili, eds., Nutrition and Nutritive Soul in Aristotle and Aristotelianism. Berlin.

Matthen, M. (2013). Teleology in Living Things. In: G. Anagnostopoulos, ed., A Companion to Aristotle. Hoboken, pp. 335-47.

Matthews, G. B. (1992). De Anima 2.2-4 and the Meaning of Life. In: M. C. Nussbaum and A. O. Rorty, eds., Essays on Aristotle's De Anima. Oxford, pp. 185-93.

Menn, S. (2002). Aristotle's Definition of Soul and the Programme of the De Anima. Oxford Studies in Ancient Philosophy 22, pp. 83-139.

Moraux, P. (1955). À propos du voṽ $\theta u ́ p \alpha \theta \varepsilon v$ chez Aristote. In: Autour d'Aristote: recueil d'études de philosophie ancienne et médiévale offert à Monseigneur A. Mansion. Louvain, pp. 255-95.

Nussbaum, M. C., ed. and trans. (1978). Aristotle's De Motu Animalium. Princeton.

Peck, A. L., ed. and trans. (1942). Aristotle: Generation of Animals. Cambridge.

Pellegrin, P. (2018). What is Aristotle's Generation of Animals About? In: A. Falcon and D. Lefebvre, eds., Aristotle's Generation of Animals: A Critical Guide. Cambridge, pp. 77-88.

Platt, A., trans. (1912). De Generatione Animalium. In: J. A. Smith and W. D. Ross, eds., The Works of Aristotle, vol. 5. Oxford.

Polansky, R. M. (2007). Aristotle’s De Anima. Cambridge.

Quarantotto, Diana. (2005). Causa finale, sostanza ed essenza in Aristotele: Saggio sulla struttura dei processi teleologici naturali e sulla funzione dei telos. Naples.

Quarantotto, Diana. (forthcoming). Aristotle on the Order of Embryonic Development and the Homonymy Principle. In: S. Föllinger, ed., Aristotle's Generation of Animals: A Comprehensive Approach. Stuttgart. Rashed, M. (2002). La préservation ( $\sigma \omega \tau \eta \rho i ́ \alpha)$, objet des Parva Naturalia et ruse de la nature. Revue de philosophie ancienne 20, pp. 35-59. 
de Ribera-Martin, I. (2019). Movement (kinêsis) as Efficient Cause in Aristotle's Generation of Animals.

HOPOS: The Journal of the International Society for the History of Philosophy of Science 9, pp. 296-326.

Rodier, G. (1900). Aristote, Traité de L'ame, Tome II: Notes. Paris.

Ross, W. D., ed. (1948). Aristotle's Metaphysics, vol. 1. Oxford.

Ross, W. D., ed. (1955). Aristotle, Parva Naturalia. Oxford.

Ross, W. D., ed. (1956). Aristotelis: De Anima. Oxford.

Ross, W. D., ed. (1961). Aristotle, De Anima. Oxford.

Sachs, J., trans. (2004). Aristotle's On the Soul and On Memory and Recollection. Santa Fe, NM.

Sedley, D. (2002). Aristotelian Relativities. In: M. Canto-Sperber and P. Pellegrin, eds., Le style de la pensée.

Paris, pp. 324-52.

Shields, C., trans. (2016). Aristotle: De Anima. Oxford.

Shiffman, M., trans. (2011). Aristotle: De Anima. Newburyport.

Smyth, H. W. (1984). Greek Grammar. Revised by G. M. Messing. Cambridge.

Taylor, R. C., trans. (2009). Averroes: Long Commentary on the De Anima of Aristotle. New Haven.

van Emde Boas, E., Rijksbaron, A., Huitink, L. and de Bakker M. (2019). The Cambridge Grammar of Classical Greek. Cambridge. 